\title{
ECONOMICS
}

\section{THE PAY PARITY MATRIX A TOOL FOR ANALYSING THE STRUCTURE OF PAY}

by

Kenneth W Clements and

Izan H Y Izan

Business School

The University of Western Australia 
14 July 2010

\title{
THE PAY PARITY MATRIX \\ A TOOL FOR ANALYSING THE STRUCTURE OF PAY*
}

by

Kenneth W Clements

And

Izan H Y Izan

Business School

The University of Western Australia

\begin{abstract}
$\underline{\text { Abstract }}$
This paper introduces a new tool for measuring relative pay within organisations, which we call the "pay parity (PP) matrix" and discusses its advantages and useful properties. The PP matrix allows us to conveniently measure, and draw inferences about, the nature of the whole remuneration schedule, such as its gradient and smoothness. We illustrate the application of the PP matrix by using data on the remuneration of academic executives. This tool has wider uses whenever matrix comparisons are involved.
\end{abstract}

*We thank Germaine Chin and Ze Min Hu for excellent research assistance. We also thank Ze Min Hu, Paul Miller, Giri Parameswaran and Jiawei Si for helpful comments. This research was in part financed by the ARC and the Business School at UWA. 


\section{Introduction}

Consider an organisation that has $\mathrm{n}$ levels of employees with level 1 the highest paying and level $\mathrm{n}$ the lowest; denote by $P_{i}$ the pay received by those at level $i$, so the remuneration schedule is $P_{1}, \ldots, P_{n}$. How can we efficiently summarise the distribution of pay within the organisation? In this paper, we show this apparently innocuous question leads to further questions and issues that are quite rich in their implications. We start by discussing alternative ways of measuring relative pay, which leads to what we call the "the pay parity matrix", a matrix that compares the pay at each level with all others. This is followed by a detailed statistical analysis of the properties of the matrix and we show how it can be used to conveniently summarise the schedule it terms of its gradient and degree of "smoothness". Toward the end of the paper, we illustrate the estimation of the PP matrix with data drawn from a number of organisations.

\section{Possible Measures of Relative Pay}

One approach to relative pay is to express each level of pay as a deviation from the top, $\mathrm{P}_{\mathrm{i}}-\mathrm{P}_{1}, \mathrm{i}=2, \ldots, \mathrm{n}$. But as these differences are expressed in dollars whose value changes from year to year and country to country, this is not the best way to proceed. Two related unit-free measures, the ratio $R_{i 1}=P_{i} / P_{1}$ and the percentage difference $P_{i 1}^{\prime}=100 \times\left(P_{i}-P_{1}\right) / P_{1}=100 \times\left(R_{i 1}-1\right)$, are also possible measures. While these represent improvements over the difference, they are still not wholly satisfactory. Instead we use the logarithmic ratio, defined as $\pi_{\mathrm{i} 1}=\log \mathrm{R}_{\mathrm{i} 1}=\log \left(\mathrm{P}_{\mathrm{i}} / \mathrm{P}_{1}\right)$, which we shall call the "parity" between the remuneration of level $\mathrm{i}$ and that of the top. The advantages of this parity measure are outlined below.

Consider the more general case of the comparison of remuneration at level $\mathrm{i}$ with any other level $\mathrm{j}$, which may be above or below i. For each pair of levels $(i, j), i, j=1, \ldots, n$, denote the ratio of $P_{i}$ to $P_{j}$ by $\mathrm{R}_{\mathrm{ij}}=\mathrm{P}_{\mathrm{i}} / \mathrm{P}_{\mathrm{j}}$, the percentage difference by $\mathrm{P}_{\mathrm{ij}}^{\prime}=100 \times\left(\mathrm{P}_{\mathrm{i}}-\mathrm{P}_{\mathrm{j}}\right) / \mathrm{P}_{\mathrm{j}}=100 \times\left(\mathrm{R}_{\mathrm{ij}}-1\right)$ and the parity by $\pi_{\mathrm{ij}}=\log \left(\mathrm{P}_{\mathrm{i}} / \mathrm{P}_{\mathrm{j}}\right)$. The relationship between the percentage difference and the parity is $\mathrm{P}_{\mathrm{ij}}^{\prime}=100 \times\left(\mathrm{e}^{\pi_{\mathrm{ij}}}-1\right)$.

Figure 1 illustrates the relation between the three measures of relative pay, the ratio, the percentage difference and the logarithmic ratio. When level $\mathrm{i}$ is below $\mathrm{j}$, the ratio $\mathrm{R}_{\mathrm{ij}}<1, \mathrm{P}_{\mathrm{ij}}^{\prime}<0$ and $\pi_{\mathrm{ij}}<0$, and vice versa when $\mathrm{i}>\mathrm{j}$. For example, when the remuneration at level $\mathrm{i}$ is one-half that of $\mathrm{j}$, the ratio $\mathrm{R}_{\mathrm{ij}}=1 / 2$, the percentage difference $P_{i j}^{\prime}=-50$ percent and the parity $\pi_{i j} \times 100=-69$. As can be seen from the figure, the percentage difference is never less than the parity $(\times 100)$ and when the two levels of pay $i$ and $j$ are sufficiently “close", $\mathrm{R}_{\mathrm{ij}} \approx 1$, and $\mathrm{P}_{\mathrm{ij}}^{\prime} \approx 100 \times \pi_{\mathrm{ij}}$. 
The use of the parity $\pi_{\mathrm{ij}}$ to make relative comparisons between different levels of remuneration has three distinct advantages:

1. Independence of irrelevant levels. Consider the percentage difference between the pay at levels $\mathrm{i}$ and $\mathrm{j}$, and that between the adjacent level $\mathrm{i}-1$ and $\mathrm{j}, \mathrm{P}_{\mathrm{ij}}^{\prime}$ and $\mathrm{P}_{\mathrm{i}-1, \mathrm{j}}^{\prime}$, respectively. Can these be used to compare pay at levels $\mathrm{i}$ and $\mathrm{i}-1$ ? The difference between these two percentages is $\mathrm{P}_{\mathrm{ij}}^{\prime}-\mathrm{P}_{\mathrm{i}-1, \mathrm{j}}^{\prime}=100 \times\left(\mathrm{P}_{\mathrm{i}}-\mathrm{P}_{\mathrm{i}-1}\right) / \mathrm{P}_{\mathrm{j}}$, which is the difference in pay between levels $\mathrm{i}$ and $\mathrm{i}-1$ as a percentage of that of level $\mathrm{j}$. This measure is a bit cumbersome as it involves a three-way comparison of levels $\mathrm{i}$, i-1 and j. By contrast, the difference in the corresponding parities is $\pi_{\mathrm{ij}}-\pi_{\mathrm{i}-1, \mathrm{j}}=\log \left(\mathrm{P}_{\mathrm{i}} / \mathrm{P}_{\mathrm{j}}\right)-\log \left(\mathrm{P}_{\mathrm{i}-1} / \mathrm{P}_{\mathrm{j}}\right)=\log \left(\mathrm{P}_{\mathrm{i}} / \mathrm{P}_{\mathrm{i}-1}\right)$, which has no such problem as it involves a direct comparison of only the pay at the relevant two levels, with no reference to that of the irrelevant base $\mathrm{j}$. In other words, the difference in the parities $\pi_{\mathrm{ij}}-\pi_{\mathrm{i}-1, \mathrm{j}}$ is just the parity of level $\mathrm{i}$ relative to level $\mathrm{i}-1$, viz., $\pi_{\mathrm{i} . \mathrm{i}-1}$. This attractive "triangularity" property carries over to all higher-order comparisons of the form $\pi_{\mathrm{i}, \pm \pm \mathrm{k}}=\pi_{\mathrm{ij}}-\pi_{\mathrm{i} \pm \mathrm{k}, \mathrm{j}}$, where the comparator level can be either below (for $\mathrm{k}<0$ ) or above $(\mathrm{k}>0)$ the initial level i. In this sense, the parity is independent of irrelevant levels, or more simply, is base invariant.

2. Symmetry. Suppose that an employee at level i earns $\beta>0$ percent less than the highest-paid employee of the organisation ("the boss"), so that $\mathrm{P}_{\mathrm{i} 1}^{\prime}=-\beta<0$. As percentage differences are not symmetric, that is $\left(\mathrm{P}_{1}-\mathrm{P}_{\mathrm{i}}\right) / \mathrm{P}_{\mathrm{i}} \neq-\left(\mathrm{P}_{\mathrm{i}}-\mathrm{P}_{1}\right) / \mathrm{P}_{1}=\beta / 100$, the boss does not earn $\beta$ percent more than level $\mathrm{i}$, which seems contradictory. The parity, by contrast, is not subject to this asymmetry as $-\pi_{\mathrm{i} 1}=\log \left(\mathrm{P}_{1} / \mathrm{P}_{\mathrm{i}}\right)=\pi_{\mathrm{li}}$; in words, if $\mathrm{i}$ earns $-\pi_{\mathrm{i} 1}>0$ less than the boss, then the boss earns $\pi_{\mathrm{i} 1}$ more than $\mathrm{i}$.

3. Unrestricted domain. As pay is always positive, the pay of any level cannot be less than 100 percent below that of any other level. Accordingly, the range of the percentage differences $\mathrm{P}_{\mathrm{ij}}^{\prime}$ is restricted to $[-100, \infty]$, while that of the parity $\pi_{\mathrm{ij}}$ is $[-\infty, \infty]$. This unrestricted domain property has statistical attractions including the avoidance of a tendency to a skewed distribution associated with the truncated lower limit of the percentage measure.

\section{The Pay Parity Matrix}

The whole remuneration schedule can be characterised by the $n^{2}$ parities $\pi_{i j}$ for $i, j=1, \ldots, n$. These can be conveniently arranged in the form of an $n \times n$ matrix $\boldsymbol{\Pi}$, which we dub "the pay parity matrix". 1 This matrix has the $(i, j)^{\text {th }}$ element $\pi_{i j}=\log \left(P_{i} / P_{j}\right)$, which is remuneration of level $i$ relative to j. As $P_{i}>P_{i+1}, i=1, \ldots, n$, by construction as we move from left to right along a given row of $\Pi$, the

\footnotetext{
${ }^{1}$ In Clements and Izan (2008), we used the pay parity matrix to analyse the remuneration of Australian academic executives.
} 
parities increase since we are comparing the pay of a given-level employee $\left(\mathrm{P}_{\mathrm{i}}\right)$ with that of successively lower-paid employees -- the boss, number 2, number 3, and so on.

To illustrate, we use remuneration data referring to what we call "academic-executives" at The University of Western Australia, given in column 2 of Table 1. As can be seen, the highest-earning employee (the Vice-Chancellor) receives $\$ A 485,000$ p. a., while the next four levels earn $\$ 335,000$, $\$ 305,000, \$ 295,000, \$ 275,000$, respectively. The second last element of column 2 shows that the arithmetic mean remuneration is $\$ 339,000$, while, from column 3 , the geometric mean is $\exp (12.7122) \approx \$ 332,000$. The corresponding pay parity matrix $\Pi$ is of order $5 \times 5$ and is given in rows 1-5 and columns 4-8 of the table. Moving from left to right across the first row, we see that level 1 receives about 37 percent more than level 2, 46 percent more than 3, 50 percent more than 4 and 57 percent more than 5 . The other elements of the table are discussed below when we introduce the various properties of $\boldsymbol{\Pi}$.

Let $\mathrm{p}_{\mathrm{i}}=\log \mathrm{P}_{\mathrm{i}}$, so that $\pi_{\mathrm{ij}}=\mathrm{p}_{\mathrm{i}}-\mathrm{p}_{\mathrm{j}}$. We can then express the pay parity (PP) matrix in the form

$$
\Pi=\mathbf{p l}^{\prime}-\mathbf{l} \mathbf{p}^{\prime},
$$

where $\mathbf{p}=\left[\mathrm{p}_{1}, \ldots, \mathrm{p}_{\mathrm{n}}\right]^{\prime}$ is a vector of the $\mathrm{n}$ levels of remuneration (in logarithmic form), and $\mathbf{\imath}=[1, \ldots, 1]^{\prime}$ is a vector of $\mathrm{n}$ unit elements. Suppose we multiply the remuneration schedule by some positive constant $\lambda$, so that it becomes $\left[\mathrm{P}_{1}^{1}, \ldots, \mathrm{P}_{\mathrm{n}}^{1}\right]^{\prime}=\left[\lambda \mathrm{P}_{1}^{0}, \ldots, \lambda \mathrm{P}_{\mathrm{n}}^{0}\right]^{\prime}$. For example, this $\lambda$ could be an adjustment for inflation, or an exchange rate that converts from one currency to another. Using a zero (one) superscript to denote the old (new) remuneration vector, in logarithmic terms, we have $\mathbf{p}^{1}=\left[\log \mathrm{P}_{1}^{0}, \ldots, \log \mathrm{P}_{\mathrm{n}}^{0}\right]^{\prime}+[\log \lambda, \ldots, \log \lambda]^{\prime}$, which can be expressed as $\mathbf{p}^{1}=\mathbf{p}^{0}+(\log \lambda) \mathbf{\imath}$. Definition (1) then implies that the new PP matrix $\boldsymbol{\Pi}^{1}$ coincides with the old one $\boldsymbol{\Pi}^{0}$ as

$$
\boldsymbol{\Pi}^{1}=\mathbf{p}^{1} \mathfrak{\imath}^{\prime}-\mathbf{l}\left(\mathbf{p}^{1}\right)^{\prime}=\mathbf{p}^{0} \mathfrak{l}^{\prime}+(\log \lambda) \mathfrak{u} \mathfrak{l}^{\prime}-\left[\mathbf{l}\left(\mathbf{p}^{0}\right)^{\prime}+(\log \lambda) \mathfrak{u}^{\prime}\right]=\boldsymbol{\Pi}^{0} .
$$

In this case, the PP matrix is unchanged as it involves only relative comparisons. Thus we can say that $\mathbf{\Pi}$ is homogeneous of zero degree in the remuneration vector when expressed in terms of dollars, $\left[\mathrm{P}_{1}, \ldots, \mathrm{P}_{\mathrm{n}}\right]$, or that $\boldsymbol{\Pi}$ is subject to additive degree of freedom. We record this as Property 1:

Property 1 The pay parity matrix $\boldsymbol{\Pi}$ is invariant to multiplicative scaling of the remuneration schedule.

Definition (1) also implies that $\boldsymbol{\Pi}$ is a skew-symmetric matrix, that is, the diagonal elements are all zero, while $\pi_{\mathrm{ij}}=-\pi_{\mathrm{ji}}, \mathrm{i}, \mathrm{j}=1, \ldots, \mathrm{n}$. Thus:

Property 2 The pay parity matrix $\boldsymbol{\Pi}$ is skew-symmetric. 
This property is clear from the PP matrix of Table 1, where, for example, level 1 earns 37 percent more than level 2 [element $(1,2)$ of the matrix], while 2 earns 37 percent less than 1 [element $(2,1)$ ]. This property represents an internal consistency of PP matrix comparisons.

\section{First and Second Moments}

Consider the $\mathrm{i}^{\text {th }}$ row of $\boldsymbol{\Pi},\left[\pi_{\mathrm{i} 1}, \ldots, \pi_{\mathrm{in}}\right]$. One way in which the information contained in the whole row can be summarised in terms of one number, $\pi_{\mathrm{i}}$, is by the value that minimises the sum of

squared deviations, $\sum_{\mathrm{j}=1}^{\mathrm{n}}\left(\pi_{\mathrm{ij}}-\pi_{\mathrm{i}}\right)^{2}$. This leads to $\pi_{\mathrm{i}}$ being the mean of the row, which we shall denote by $\bar{\pi}_{\mathrm{i}}=(1 / \mathrm{n}) \sum_{\mathrm{j}=1}^{\mathrm{n}} \pi_{\mathrm{ij}}$, or $\bar{\pi}=(1 / \mathrm{n}) \boldsymbol{\Pi} \mathbf{\imath}$ for the corresponding vector of $\mathrm{n}$ row means. The vector $\bar{\pi}$ is a desirable centre-of-gravity measure of the whole $\Pi$ matrix in a least-squares sense. Denoting (the $\log$ of geometric) mean remuneration by

$$
\overline{\mathrm{p}}=\frac{1}{\mathrm{n}} \sum_{\mathrm{j}=1}^{\mathrm{n}} \mathrm{p}_{\mathrm{j}}=\frac{1}{\mathrm{n}} \mathbf{\imath}^{\prime} \mathbf{p}
$$

it then follows from definition (1) that the row averages take the form

$$
\bar{\pi}=\frac{1}{\mathrm{n}} \Pi \mathbf{\imath}=\frac{1}{\mathrm{n}}\left(\mathbf{p} \mathbf{\imath}^{\prime}-\mathbf{\imath} \mathbf{p}^{\prime}\right) \mathbf{\imath}=\mathbf{p}-\overline{\mathrm{p}} \mathbf{\imath},
$$

where the last step is based on $\mathbf{\imath}^{\prime} \mathbf{\imath}=\mathrm{n}$. The last member of equation (3) states that the averages of the rows of the PP matrix are just the deviations of each level of remuneration from the overall mean. That is, $\bar{\pi}_{i}=p_{i}-\bar{p}, i=1, \ldots, n$, where $\bar{\pi}_{i}$ is the $i^{\text {th }}$ element of $\bar{\pi}$. Equation (3) can be expressed more compactly as

$$
\overline{\boldsymbol{\pi}}=\mathbf{M} \mathbf{p}, \text { with } \mathbf{M}=\mathbf{I}-\frac{1}{\mathrm{n}} \mathbf{u}^{\prime},
$$

where $\mathbf{M}$ is a symmetric idempotent matrix $\left(\mathbf{M}^{2}=\mathbf{M}\right)$ of order $\mathrm{n} \times \mathrm{n}$ that satisfies $\mathbf{M} \mathbf{\imath}=\mathbf{0}$. As $\mathbf{M}$ is symmetric, $\mathfrak{\imath}^{\prime} \mathbf{M}=\mathbf{0}^{\prime}$, which implies that $\mathfrak{\imath}^{\prime} \overline{\boldsymbol{\pi}}=\mathfrak{\imath}^{\prime} \mathbf{M p}=0$. Thus, the sum over all levels of the deviations from the mean is zero.

We summarise the above discussion as follows:

Property 3 The average of the elements in the $i^{\text {th }}$ row of the pay parity matrix is the logarithmic deviation of remuneration at level $i$ from the mean.

Column 9 of Table 1 contains the row averages of the PP matrix, and shows that level 1 earns about 38 percent more than the (geometric) mean, level 2 earns 1 percent more, and so on. Interestingly, these row averages are close to the elements of column 2 of the PP matrix, which reflects the fact that in this example remuneration at level 2 is close to the mean. The sum (and average) of these deviations from the mean is zero, as indicated by the second last entry of column 9.

As the PP matrix is a mapping of the remuneration vector $\mathbf{p}$ from $\mathbb{R}^{\mathrm{n}}$ into $\mathbb{R}^{2 \mathrm{n}}$, we can write it as the function $\Pi=\Pi(\mathbf{p})=\mathbf{p r}^{\prime}-\mathbf{\imath} \mathbf{p}^{\prime}$. Interestingly, if we apply $\Pi(\cdot)$ to the vector of deviations from the 
mean $\bar{\pi}$, rather than $\mathbf{p}$, we obtain the original PP matrix associated with $\mathbf{p}$. That is, $\Pi(\overline{\boldsymbol{\pi}})=\bar{\pi} \mathfrak{\imath}^{\prime}-\mathbf{\imath} \bar{\pi}^{\prime}=\mathbf{p}^{\prime}-\mathbf{\imath} \mathbf{p}^{\prime}=\Pi(\mathbf{p})$, which follows from definition (4) and is a type of self-reflective property. This result is a reflection of Property 1 whereby the PP matrix is invariant to multiplicative scaling of the remuneration schedule. When we express remuneration in terms of logarithmic deviations from the geometric mean, this amounts to a choice of units for remuneration by deflating by the geometric mean. More generally, if instead of the mean we subtract some $\alpha>0$ from each element of $\mathbf{p}$, so that the "scaled" remuneration vector is $\mathbf{p}-\alpha \mathbf{l}$, then the associated PP matrix is $\Pi(\mathbf{p}-\alpha \mathbf{l})$, which is identical to the original matrix $\Pi(\mathbf{p})$.

How is remuneration of the organisation dispersed about the mean? One way to measure dispersion is by the variance of remuneration:

$$
\sigma^{2}=\frac{1}{n} \sum_{i=1}^{n}\left(p_{i}-\bar{p}\right)^{2}=\frac{1}{n}(\mathbf{p}-\bar{p} \mathbf{l})^{\prime}(\mathbf{p}-\bar{p} \mathbf{l})=\frac{1}{n} \bar{\pi}^{\prime} \bar{\pi}=\frac{1}{n} \sum_{i=1}^{n} \bar{\pi}_{i}^{2},
$$

where the third step follows from equation (3). Accordingly,

\section{Property 4 The variance of remuneration is the average of the sum of the squared} row averages of the pay parity matrix.

The last entry of column 3 of Table 1 shows that the logarithmic standard deviation of the remuneration schedule is 0.2002 , or about 20 percent; thus the variance is $(0.2002)^{2}=0.0401$. Column 10 presents the squares of the row averages, and their mean of $4.01 \times 10^{-2}$, given as the last element of the column, is identical to the above variance.

It is also to be noted that equations (4) and (5) imply that the variance can also be expressed as $\sigma^{2}=(1 / \mathrm{n}) \mathbf{p}^{\prime} \mathbf{M}^{\prime} \mathbf{M p}$. But as $\mathbf{M}$ is idempotent, this simplifies to

$$
\sigma^{2}=\frac{1}{\mathrm{n}} \mathbf{p}^{\prime} \mathbf{M p}
$$

Next, consider the dispersion of the elements of the $i^{\text {th }}$ row of the pay parity matrix about their centre of gravity, as well as their comovement with the elements of some other row. The following variance and covariance provide a convenient way to measure these concepts:

$$
\sigma_{\mathrm{ii}}=\frac{1}{\mathrm{n}} \sum_{\mathrm{j}=1}^{\mathrm{n}}\left(\pi_{\mathrm{ij}}-\bar{\pi}_{\mathrm{i}}\right)^{2}, \quad \sigma_{\mathrm{ik}}=\frac{1}{\mathrm{n}} \sum_{\mathrm{j}=1}^{\mathrm{n}}\left(\pi_{\mathrm{ij}}-\bar{\pi}_{\mathrm{i}}\right)\left(\pi_{\mathrm{kj}}-\bar{\pi}_{\mathrm{k}}\right) .
$$

This $\sigma_{\mathrm{ii}}$ is the variance of the $\mathrm{i}^{\text {th }}$ row of the PP matrix, while $\sigma_{\mathrm{ik}}$ is the covariance between rows $\mathrm{i}$ and $\mathrm{k}$.

The matrix $\Pi-\bar{\pi} \iota^{\prime}$ is PP expressed as a deviation from the mean vector $\bar{\pi}$. The covariance matrix $\boldsymbol{\Omega}=(1 / \mathrm{n})\left(\boldsymbol{\Pi}-\overline{\boldsymbol{\pi}} \mathbf{\imath}^{\prime}\right)\left(\boldsymbol{\Pi}-\bar{\pi} \mathrm{\imath}^{\prime}\right)^{\prime}$ contains on the diagonal the $\mathrm{n}$ row variances $\sigma_{11}, \ldots, \sigma_{\mathrm{nn}}$ and the cross-row covariances $\sigma_{\mathrm{ik}}$ as the off-diagonal elements. As $\bar{\pi}=(1 / \mathrm{n}) \boldsymbol{\Pi} \mathbf{\imath}$, it follows that the above deviation matrix takes the form 


$$
\Pi-\bar{\pi} \imath^{\prime}=\Pi-\frac{1}{n} \Pi \imath^{\prime}=\Pi\left[I-\frac{1}{n} \mathfrak{l}^{\prime}\right]=\Pi M,
$$

where $\mathbf{M}$ is defined in equation (4). Thus as $\mathbf{M}$ is idempotent, the covariance matrix $\boldsymbol{\Omega}$ becomes a multiple $1 / \mathrm{n}$ of

$$
\begin{aligned}
& \left(\Pi-\bar{\pi} \iota^{\prime}\right)\left(\Pi-\bar{\pi} \iota^{\prime}\right)^{\prime}=\Pi M \Pi^{\prime} \\
& =\left(\mathbf{p} \mathbf{\imath}^{\prime}-\mathbf{v} \mathbf{p}^{\prime}\right) \mathbf{M}\left(\mathbf{l} \mathbf{p}^{\prime}-\mathbf{p} \mathbf{\imath}^{\prime}\right) \\
& =\left(\mathbf{p} \mathbf{\imath}^{\prime} \mathbf{M}-\mathbf{\imath} \mathbf{p}^{\prime} \mathbf{M}\right)\left(\mathbf{\imath} \mathbf{p}^{\prime}-\mathbf{p} \mathbf{\imath}^{\prime}\right) \\
& =\mathbf{t p}^{\prime} \mathbf{M p r}^{\prime} \\
& =n \sigma^{2} \mathbf{u t}^{\prime} \text {. }
\end{aligned}
$$

The fourth line of the above follows from $\mathbf{\imath}^{\prime} \mathbf{M}=\mathbf{0}^{\prime}$ and $\mathbf{M} \mathbf{\imath}=\mathbf{0}$, while the fifth is based on equation (6). Thus we have $\boldsymbol{\Omega}=\sigma^{2} \mathbf{l l}^{\prime}$, so that

$$
\sigma_{\mathrm{ii}}=\sigma_{\mathrm{ik}}=\sigma^{2}, \quad \mathrm{i}, \mathrm{k}=1, \ldots, \mathrm{n} .
$$

In words, each row of the PP matrix has a common variance $\sigma^{2}$, and each of the distinct $1 / 2[n(n-1)]$ covariances $^{2}$ also takes this value. In view of the skew-symmetric nature of $\boldsymbol{\Pi}$ (Property 2 ), each column of the matrix also has a common variance $\sigma^{2}$. The quantity $\sigma^{2}$ is the variance of the remuneration schedule defined in equation (5). Accordingly,

Property 5 The variance of each row and column of the PP matrix takes the same value, $\sigma^{2}$, the variance of the remuneration schedule. Furthermore, each covariance between pairs of different rows (and columns) of this matrix is also equal to $\sigma^{2}$.

As discussed above, the standard deviation of the UWA remuneration schedule is $\sigma=0.2002$. The last column of Table 1 contains the standard deviation (SD) of each row of $\boldsymbol{\Pi}$, and as can be seen, each value here is $20.02 \times 10^{-2}$, the SD of the remuneration schedule. The same result applies to the SDs of the columns of $\boldsymbol{\Pi}$, which are given as the last entries in columns 4-8 of Table 1 .

The average sum of squares of the PP matrix is also of interest. This takes the form $\left(1 / \mathrm{n}^{2}\right) \sum_{\mathrm{i}=1}^{\mathrm{n}} \sum_{\mathrm{j}=1}^{\mathrm{n}} \pi_{\mathrm{ij}}^{2}=\left(1 / \mathrm{n}^{2}\right) \operatorname{tr}\left(\boldsymbol{\Pi} \boldsymbol{\Pi}^{\prime}\right)$, where $\operatorname{tr}$ denotes the trace operator. Defining $\bar{\alpha}^{2}=(1 / n) \sum_{i=1}^{n} p_{i}^{2}=(1 / n) \mathbf{p}^{\prime} \mathbf{p}$ as average squared remuneration, in view of equation (1) we have

$$
\begin{aligned}
& \left(1 / \mathbf{n}^{2}\right) \operatorname{tr}\left(\boldsymbol{\Pi} \boldsymbol{\Pi}^{\prime}\right)=\left(1 / \mathbf{n}^{2}\right) \operatorname{tr}\left(\mathbf{p} \mathbf{\imath}^{\prime}-\mathbf{i} \mathbf{p}^{\prime}\right)\left(\mathbf{\mathbf { p } ^ { \prime }}-\mathbf{p} \mathbf{\imath}^{\prime}\right) \\
& =\left(1 / \mathrm{n}^{2}\right) \operatorname{tr}\left(\mathbf{p} \mathbf{\imath}^{\prime} \mathbf{i} \mathbf{p}^{\prime}-\mathbf{p} \mathbf{\imath}^{\prime} \mathbf{p} \mathbf{\imath}^{\prime}-\mathbf{z} \mathbf{p}^{\prime} \mathbf{i} \mathbf{p}^{\prime}+\mathbf{p} \mathbf{p}^{\prime} \mathbf{p} \mathbf{\imath}^{\prime}\right) \\
& =\left(1 / n^{2}\right) \operatorname{tr}\left(n \mathbf{p} \mathbf{p}^{\prime}-n \bar{p} \mathbf{p} \mathbf{\imath}^{\prime}-n \bar{p} \mathbf{p} \mathbf{p}^{\prime}+n \bar{\alpha}^{2} \mathbf{u}^{\prime}\right) \\
& =\left(1 / n^{2}\right)\left(n^{2} \bar{\alpha}^{2}-n^{2} \bar{p}^{2}-n^{2} \bar{p}^{2}+n^{2} \bar{\alpha}^{2}\right) \\
& =2\left(\bar{\alpha}^{2}-\overline{\mathrm{p}}^{2}\right) \text {. }
\end{aligned}
$$

\footnotetext{
${ }^{2}$ The correlation matrix corresponding to $\boldsymbol{\Omega}$ takes the form $\mathbf{u}^{\prime}$, so that each correlation is unity.
} 
As $\bar{\alpha}^{2}-\bar{p}^{2}=(1 / n) \sum_{i=1}^{n}\left(p_{i}-\bar{p}\right)^{2}=\sigma^{2}$, we finally obtain

$$
\frac{1}{n^{2}} \sum_{i=1}^{n} \sum_{j=1}^{n} \pi_{i j}^{2}=2 \sigma^{2}
$$

In words, the average sum of squares of the elements of the PP matrix is twice the variance of remuneration.

Equation (1) implies that the mean of the $\mathrm{n}^{2}$ elements of $\boldsymbol{\Pi}$ is zero as, so the average sum of squares of the elements of $\boldsymbol{\Pi}$ is also the variance. ${ }^{3}$ Result (8) then implies that the variance of $\boldsymbol{\Pi}$ is $2 \sigma^{2}$. The multiple 2 here derives from the nature of the $\boldsymbol{\Pi}$ matrix which involves all the bivariate comparisons $(i, j)$, for $i, j=1, \ldots, n$. In particular, these $n^{2}$ comparisons include level $i$ with level $j$, as well as the reciprocal comparison of $\mathrm{j}$ with $\mathrm{i}$, so that the whole matrix contains $\pi_{\mathrm{ij}}=\mathrm{p}_{\mathrm{i}}-\mathrm{p}_{\mathrm{j}}$ and $\pi_{\mathrm{ji}}=\mathrm{p}_{\mathrm{j}}-\mathrm{p}_{\mathrm{i}}=-\pi_{\mathrm{ij}}$ for $i, j=1, \ldots, n$. Thus, when we square the elements of $\Pi$, the minus signs disappear and in essence each distinct pair $(\mathrm{i}, \mathrm{j})$ is included twice in the average sum of squares $\left(1 / \mathrm{n}^{2}\right) \sum_{\mathrm{i}=1}^{\mathrm{n}} \sum_{\mathrm{j}=1}^{\mathrm{n}} \pi_{\mathrm{ij}}^{2}{ }^{4}$ We can summarise the above results as:

Property 6 The elements of the PP matrix have a zero mean and a variance equal to $2 \sigma^{2}, \sigma^{2}$ being the variance of the remuneration schedule.

The bottom of Table 1 shows that the average sum of squares of the elements of the PP matrix is $8.01 \times 10^{-2}$, which is twice the variance of the remuneration schedule, $\sigma^{2}=4.01 \times 10^{-2}$.

\section{The Gradient and Smoothness of the Remuneration Schedule}

The remuneration schedule, expressed in logarithmic form, ranked from the highest to the lowest, is $\mathrm{p}_{1}, \ldots, \mathrm{p}_{\mathrm{n}}$. Suppose initially that it is not possible to skip any level when getting promoted. Thus, for example, an employee at the bottom of the hierarchy currently earning $p_{n}$ faces the prospect of getting promoted to level $n-1$ and receiving $p_{n-1}$. Such a promotion brings a pay rise of $\mathrm{p}_{\mathrm{n}-1}-\mathrm{p}_{\mathrm{n}}=\log \left(\mathrm{P}_{\mathrm{n}-1} / \mathrm{P}_{\mathrm{n}}\right)=\pi_{\mathrm{n}-1, \mathrm{n}}$. Similarly, subsequent promotions yield $\pi_{\mathrm{n}-2, \mathrm{n}-1}, \pi_{\mathrm{n}-3, \mathrm{n}-2}, \ldots, \pi_{1,2}$. This means that we can read off from the pay parity matrix the entire set of pay increases, in relative terms, from the bottom to the top, as the consecutive parities $\pi_{\mathrm{i}-1, \mathrm{i}}, \mathrm{i}=\mathrm{n}, \ldots, 2$, that is, the elements on the subdiagonal immediately to the right of the main diagonal, read from the bottom right-hand corner to the top

\footnotetext{
${ }^{3}$ The term "variance of $\boldsymbol{\Pi}$ " is to be interpreted as meaning the variance of the $n^{2}$ elements of this matrix, vec $\boldsymbol{\Pi}$.

4 An alternative way to establish result (8) is as follows: Recall the covariance matrix introduced below equation (6), $\boldsymbol{\Omega}=(1 / \mathrm{n})\left(\boldsymbol{\Pi}-\overline{\boldsymbol{\pi}} \mathbf{\imath}^{\prime}\right)\left(\boldsymbol{\Pi}-\overline{\boldsymbol{\pi}} \mathbf{l}^{\prime}\right)^{\prime}$. This can be expressed as $\boldsymbol{\Omega}=(1 / \mathrm{n})\left(\boldsymbol{\Pi} \boldsymbol{\Pi}^{\prime}-\mathrm{n} \overline{\boldsymbol{\pi}} \overline{\boldsymbol{\pi}}^{\prime}\right)$, so that $\boldsymbol{\Pi} \boldsymbol{\Pi}^{\prime}=\mathrm{n}\left(\boldsymbol{\Omega}+\overline{\boldsymbol{\pi}} \overline{\boldsymbol{\pi}}^{\prime}\right)$. As $\boldsymbol{\Omega}=\sigma^{2} \mathfrak{\imath}^{\prime}$, it follows that

$$
\operatorname{tr}\left(\boldsymbol{\Pi} \boldsymbol{\Pi}^{\prime}\right)=\mathrm{n}\left[\sigma^{2} \operatorname{tr}\left(\mathfrak{u}^{\prime}\right)+\operatorname{tr}\left(\overline{\boldsymbol{\pi}} \overline{\boldsymbol{\pi}}^{\prime}\right)\right]=\mathrm{n}\left[\sigma^{2} \mathrm{n}+\sum_{\mathrm{i}=1}^{\mathrm{n}} \bar{\pi}_{\mathrm{i}}^{2}\right]
$$

As from equation (5), $\sum_{\mathrm{i}=1}^{\mathrm{n}} \bar{\pi}_{\mathrm{i}}^{2}=\mathrm{n} \sigma^{2}$, the above becomes $\operatorname{tr}\left(\boldsymbol{\Pi} \boldsymbol{\Pi}^{\prime}\right)=2 \mathrm{n}^{2} \sigma^{2}$, from which result (8) follows directly.
} 
left. The quantities $\pi_{\mathrm{i}-1, \mathrm{i}}$ are the logarithmic differences between remuneration at each level, or the sizes of the $n-1$ steps of the schedule. The average of these $n-1$ steps is the gradient of the entire remuneration schedule, $\beta=[1 /(n-1)] \sum_{\mathrm{i}=2}^{\mathrm{n}} \pi_{\mathrm{i}-1, \mathrm{i}}$. As $\sum_{\mathrm{i}=2}^{\mathrm{n}} \pi_{\mathrm{i}-1, \mathrm{i}}=\sum_{\mathrm{i}=2}^{\mathrm{n}}\left(\mathrm{p}_{\mathrm{i}-1}-\mathrm{p}_{\mathrm{i}}\right)=\mathrm{p}_{1}-\mathrm{p}_{\mathrm{n}}$, the gradient takes the simple form

$$
\beta=\frac{\left(p_{1}-p_{n}\right)}{n-1}=\frac{\pi_{1 n}}{n-1} .
$$

This shows that the gradient is just the overall "height" of the schedule, $p_{1}-p_{n}$, per unit of its "length", the $\mathrm{n}-1$ steps.

Thus we have

Property 7 The successive steps of the remuneration schedule are given by the elements along the sub-diagonal of the pay parity matrix $\pi_{n-1, n}, \pi_{n-2, n-1}, \ldots, \pi_{1,2}$. The gradient of the entire schedule is the average of these steps. This average is a multiple $1 /(n-1)$ of the element of the PP matrix $\pi_{1 n}$, which is the logarithmic ratio of the highest to lowest pay.

Looking again at the example in Table 1, column 8, row 4 reveals that a promotion from level 5 to level 4 generates about a 7-percent pay increase, while subsequent promotions yield increases of 3 percent, 9 percent and 37 percent, respectively. The first element of column 8 is $\pi_{15}=56.74 \times 10^{-2}$, so the gradient $\beta$ defined in equation (9) is $56.74 \times 10^{-2} / 4=14.2 \times 10^{-2}$, or about 14 percent. We present in Figure 2 a plot of the four steps of the schedule, as well as the gradient.

The sequence of pay increases associated with promotion from one level to the next is $\pi_{\mathrm{i}-1, \mathrm{i}}, \mathrm{i}=\mathrm{n}, \ldots, 2$. Define the variance of this sequence as

$$
\sigma_{\Delta}^{2}=\frac{1}{n-1} \sum_{i=2}^{n}\left(\pi_{i-1, i}-\beta\right)^{2}
$$

As the gradient is defined as $\beta=[1 /(n-1)] \sum_{i=2}^{n} \pi_{i-1, i}$, if we interpret the height of each step $\pi_{i-1, i}$ as an independent "reading" on this gradient with a common variance $\sigma_{\Delta}^{2}$, then the sampling variance of the gradient is

$$
\operatorname{var} \beta=\frac{\sigma_{\Delta}^{2}}{\mathrm{n}-1}
$$

To summarise

Property 8 The standard error of the gradient of the remuneration schedule is a multiple $1 / \sqrt{n-1}$ of the standard deviation of the successive steps along the schedule $\pi_{n-1, n}, \pi_{n-2, n-1}, \ldots, \pi_{1,2}$. 
Using the data in Table 1 to evaluate the variance in equation (10), yields $\sigma_{\Delta}^{2}=(0.1335)^{2}$, so that the standard deviation is about 13.4 percent. Using this value in equation (11) together with $n-1=4$, gives a standard error of the gradient of $\sqrt{\operatorname{var} \beta}=\sqrt{(0.1335)^{2} / 4}=0.0668$ or about 6.7 percent.

If the n-1 steps of the remuneration schedule are all of equal height -- that is, if the increase from one level to the next is identical for all levels -- then the schedule could be described as being "smooth". In this case, each step size takes the identical value $\beta$, so that $\pi_{\mathrm{ij}}^{\mathrm{s}}=(\mathrm{j}-\mathrm{i}) \beta, \mathrm{i}, \mathrm{j}=1, \ldots, \mathrm{n}, \pi_{\mathrm{i}-1, \mathrm{i}}^{\mathrm{s}}=\beta$, $\mathrm{i}=2, \ldots, \mathrm{n}$, and $\mathrm{p}_{\mathrm{i}}^{\mathrm{s}}=(\mathrm{j}-\mathrm{i}) \beta+\mathrm{p}_{\mathrm{j}}^{\mathrm{s}}, \mathrm{i}, \mathrm{j}=1, \ldots, \mathrm{n}$, where the superscript $\mathrm{s}$ denotes the value under the hypothesis of "smoothness". To allow for departures of the observed values of $\pi_{\mathrm{i}-1, \mathrm{i}}$ from $\beta$, we write

$$
\pi_{\mathrm{i}-1, \mathrm{i}}=\beta+\mathrm{e}_{\mathrm{i}} \quad \mathrm{i}=2, \ldots, \mathrm{n},
$$

where $e_{i}$ is a zero-mean error term. Squaring both sides of this equation, summing over $i=2, \ldots, n$, and using $\sum_{\mathrm{i}=2}^{\mathrm{n}} \mathrm{e}_{\mathrm{i}}=0$, yields $\sum_{\mathrm{i}=2}^{\mathrm{n}} \pi_{\mathrm{i}-1, \mathrm{i}}^{2}=(\mathrm{n}-1) \beta^{2}+(\mathrm{n}-1) \sigma_{\Delta}^{2}$, where $\sigma_{\Delta}^{2}$ is the variance defined in equation (10). This shows that the total sum of squares (TSS) of the steps can be decomposed into two nonnegative components, so that the fractions

$$
\mathrm{R}^{2}=\frac{\beta^{2}}{\beta^{2}+\sigma_{\Delta}^{2}} \quad \text { and } \quad 1-\mathrm{R}^{2}=\frac{\sigma_{\Delta}^{2}}{\beta^{2}+\sigma_{\Delta}^{2}}
$$

are, respectively, the proportion of the TSS explained by smoothness of the schedule, and the proportion that is not. The value of $\mathrm{R}^{2}$ is a nonnegative fraction and is the squared correlation coefficient associated with regression (12). Accordingly,

Property 9 The value of $R^{2}$ defined in equation (13) is a measure of the extent to which the remuneration schedule is smooth. This $R^{2}$ is the share of the squared gradient in the sum of ( $i$ ) the squared gradient and (ii) the variance of the successive steps along the schedule $\pi_{n-1, n}, \pi_{n-2, n-1}, \ldots, \pi_{1,2}$.

For the data given in Table 1 , as mentioned above the gradient $\beta=14.2 \times 10^{-2}$ and $\sigma_{\Delta}^{2}=\left(13.35 \times 10^{-2}\right)^{2}$. Using these values in the first member of equation (13), we obtain

$$
\mathrm{R}^{2}=\frac{14.2^{2}}{14.2^{2}+13.4^{2}}=\frac{202}{380}=0.532
$$

Accordingly, for this remuneration schedule, smoothness accounts for a little over one-half of the total sum of squares.

We assumed above that it is not possible to skip any level when getting promoted. Now suppose this is no longer necessarily the case, so that it is possible to achieve "accelerated" promotion whereby 
some levels of the schedule are skipped. The pay increase in moving $k>0$ steps up the remuneration schedule from level $\mathrm{i}$ to $\mathrm{i}-\mathrm{k}$ is $\mathrm{p}_{\mathrm{i}-\mathrm{k}}-\mathrm{p}_{\mathrm{i}}=\pi_{\mathrm{i}-\mathrm{k}, \mathrm{i}}$. This can be decomposed into $\mathrm{k}$ one-step moves as

$$
\begin{aligned}
\mathrm{p}_{\mathrm{i}-\mathrm{k}}-\mathrm{p}_{\mathrm{i}} & =\left(\mathrm{p}_{\mathrm{i}-\mathrm{k}}-\mathrm{p}_{\mathrm{i}-\mathrm{k}-1}\right)+\left(\mathrm{p}_{\mathrm{i}-\mathrm{k}-1}-\mathrm{p}_{\mathrm{i}-\mathrm{k}-2}\right)+\ldots+\left(\mathrm{p}_{\mathrm{i}-1}-\mathrm{p}_{\mathrm{i}}\right) \\
& =\pi_{\mathrm{i}-\mathrm{k}, \mathrm{i}-\mathrm{k}-1}+\pi_{\mathrm{i}-\mathrm{k}-1, \mathrm{i}-\mathrm{k}-2}+\ldots+\pi_{\mathrm{i}-1, \mathrm{i}} .
\end{aligned}
$$

Thus we have

Property 10 Using the PPP matrix, a k-step move along the remuneration schedule is the sum of the corresponding $k$ one-step moves.

To illustrate this property in terms of Table 1, suppose someone moves from level four to level one. As $\pi_{14}=49.72 \times 10^{-2}$, this 3-step promotion entails an approximate 50-percent pay increase, which is the sum of the corresponding three one-step moves, $\pi_{34}+\pi_{23}+\pi_{21}=3.33+9.38+37.00=49.71\left(\right.$ all $\left.\times 10^{-2}\right)$.

\section{A Dummy-Variable Regression}

The above discussion deals with the pay parity matrix for an individual organisation. In this and the next section, we consider the problem of estimating a PP matrix with data from a sample of a number of organisations, and associated issues in hypothesis testing.

Let $\mathrm{p}_{\mathrm{ic}}$ be the logarithm of the remuneration for level $\mathrm{i}(\mathrm{i}=1, \ldots, \mathrm{n})$ in company (or other institution) c $(c=1, \ldots, C)$. Define the dummy variable $d_{j i c}$ as taking the value of 1 if $j=i, 0$ otherwise. Consider a regression of $\mathrm{p}_{\mathrm{ic}}$ on the $\mathrm{n}-1$ dummies, $\mathrm{d}_{2 \mathrm{ic}}, \ldots, \mathrm{d}_{\text {nic }}$ :

$$
\mathrm{p}_{\mathrm{ic}}=\alpha+\sum_{\mathrm{j}=2}^{\mathrm{n}} \beta_{\mathrm{j}} \mathrm{d}_{\mathrm{jic}}+\varepsilon_{\mathrm{ic}},
$$

where $\alpha$ is the intercept, $\beta_{\mathrm{j}}$ is the coefficient on the $\mathrm{j}^{\text {th }}$ dummy and $\varepsilon_{\mathrm{ic}}$ is a zero-mean independent disturbance term, with a constant variance $\sigma_{\varepsilon}^{2}$. It is well known that the least-squares estimate of $\alpha, \hat{\alpha}$, is the geometric mean of the remuneration of level 1 , the base level, while the estimate of $\beta_{j}, \hat{\beta}_{j}$, is the mean logarithmic difference between levels $\mathrm{j}$ and 1. For details, see the Appendix.

Suppose we have values for the first column of the pay parity matrix $\Pi, \pi_{11}, \pi_{21}, \pi_{31}, \ldots, \pi_{\mathrm{n} 1}$. Given that the $(i, j)^{\text {th }}$ element of $\boldsymbol{\Pi}$ is defined as $\pi_{i j}=p_{i}-p_{j}$, it follows that all the remaining $n-1$ columns of this matrix can be expressed in terms of the elements of the first. That is, 


$$
\left\{\begin{aligned}
{\left[\begin{array}{ccccc}
\pi_{11} & \pi_{12} & \pi_{13} & \ldots & \pi_{1 \mathrm{n}} \\
\pi_{21} & \pi_{22} & \pi_{23} & \ldots & \pi_{2 \mathrm{n}} \\
\pi_{31} & \pi_{32} & \pi_{33} & \ldots & \pi_{3 \mathrm{n}} \\
\vdots & \vdots & \vdots & & \vdots \\
\pi_{\mathrm{n} 1} & \pi_{\mathrm{n} 2} & \pi_{\mathrm{n} 3} & \ldots & \pi_{\mathrm{nn}}
\end{array}\right]=} & {\left[\begin{array}{cccccc}
0 & \mathrm{p}_{1}-\mathrm{p}_{2} & \mathrm{p}_{1}-\mathrm{p}_{3} & \ldots & \mathrm{p}_{1}-\mathrm{p}_{\mathrm{n}} \\
\mathrm{p}_{2}-\mathrm{p}_{1} & 0 & \mathrm{p}_{2}-\mathrm{p}_{3} & \ldots & \mathrm{p}_{2}-\mathrm{p}_{\mathrm{n}} \\
\mathrm{p}_{3}-\mathrm{p}_{1} & \mathrm{p}_{3}-\mathrm{p}_{2} & 0 & \ldots & \mathrm{p}_{3}-\mathrm{p}_{\mathrm{n}} \\
\vdots & \vdots & \vdots & & \vdots \\
\mathrm{p}_{\mathrm{n}}-\mathrm{p}_{1} & \mathrm{p}_{\mathrm{n}}-\mathrm{p}_{2} & \mathrm{p}_{\mathrm{n}}-\mathrm{p}_{3} & \ldots & 0
\end{array}\right] } \\
= & {\left[\begin{array}{cccccc}
0 & -\pi_{21} & -\pi_{31} & \ldots & -\pi_{\mathrm{n} 1} \\
\pi_{21} & 0 & \pi_{21}-\pi_{31} & \ldots & \pi_{21}-\pi_{\mathrm{n} 1} \\
\pi_{31}-\left(\pi_{21}-\pi_{31}\right) & 0 & \ldots & \pi_{31}-\pi_{\mathrm{n} 1} \\
\vdots & \vdots & \vdots & & \vdots \\
\pi_{\mathrm{n} 1}-\left(\pi_{21}-\pi_{\mathrm{n} 1}\right) & -\left(\pi_{31}-\pi_{\mathrm{n} 1}\right) & \ldots & 0
\end{array}\right] . }
\end{aligned}\right.
$$

As the estimate of the coefficient $\beta_{\mathrm{j}}$ in model (14), $\hat{\beta}_{\mathrm{j}}$, is the mean of $\mathrm{p}_{\mathrm{j}}-\mathrm{p}_{1}$, equation (15) demonstrates that we can estimate the elements of the first column of $\Pi$ as $\hat{\pi}_{i 1}=\hat{\beta}_{i}, i=2, \ldots, n$; those in the first row as $\hat{\pi}_{1 \mathrm{j}}=-\hat{\beta}_{\mathrm{j}}, \mathrm{j}=2, \ldots, \mathrm{n}$; and the remaining elements as $\hat{\pi}_{\mathrm{ij}}=\hat{\beta}_{\mathrm{i}}-\hat{\beta}_{\mathrm{j}}, \mathrm{i}, \mathrm{j}=2, \ldots, \mathrm{n}$. These expressions can be combined as

$$
\hat{\pi}_{\mathrm{ij}}=\hat{\beta}_{\mathrm{i}}-\hat{\beta}_{\mathrm{j}}, \quad \mathrm{i}, \mathrm{j}=1, \ldots, \mathrm{n}, \text { with } \hat{\beta}_{1}=0 .
$$

Thus we have

$$
\left[\begin{array}{ccccc}
\hat{\pi}_{11} & \hat{\pi}_{12} & \hat{\pi}_{13} & \ldots & \hat{\pi}_{1 \mathrm{n}} \\
\hat{\pi}_{21} & \hat{\pi}_{22} & \hat{\pi}_{23} & \ldots & \hat{\pi}_{2 \mathrm{n}} \\
\hat{\pi}_{31} & \hat{\pi}_{32} & \hat{\pi}_{33} & \ldots & \hat{\pi}_{3 \mathrm{n}} \\
\vdots & \vdots & \vdots & & \vdots \\
\hat{\pi}_{\mathrm{n} 1} & \hat{\pi}_{\mathrm{n} 2} & \hat{\pi}_{\mathrm{n} 3} & \ldots & \hat{\pi}_{\mathrm{nn}}
\end{array}\right]=\left[\begin{array}{ccccc}
0 & -\hat{\beta}_{2} & -\hat{\beta}_{3} & \ldots & -\hat{\beta}_{\mathrm{n}} \\
\hat{\beta}_{2} & 0 & \hat{\beta}_{2}-\hat{\beta}_{3} & \ldots & \hat{\beta}_{2}-\hat{\beta}_{\mathrm{n}} \\
\hat{\beta}_{3} & \hat{\beta}_{3}-\hat{\beta}_{2} & 0 & \ldots & \hat{\beta}_{3}-\hat{\beta}_{\mathrm{n}} \\
\vdots & \vdots & \vdots & & \vdots \\
\hat{\beta}_{\mathrm{n}} & \hat{\beta}_{\mathrm{n}}-\hat{\beta}_{2} & \hat{\beta}_{\mathrm{n}}-\hat{\beta}_{3} & \ldots & 0
\end{array}\right] .
$$

In the Appendix, we show that

$$
\operatorname{var} \hat{\alpha}=\frac{\sigma_{\varepsilon}^{2}}{C}, \quad \operatorname{var} \hat{\beta}_{j}=\frac{2 \sigma_{\varepsilon}^{2}}{C}, j=2, \ldots, n,
$$

where $\sigma_{\varepsilon}^{2}$ is the variance of the disturbance in model (14) and $C$ is the number of companies. We also show that

$$
\operatorname{var} \hat{\pi}_{i j}=\frac{2 \sigma_{\varepsilon}^{2}}{C} \quad i, j=1, \ldots, n, i \neq j .
$$

Accordingly, the sampling variances of the estimates of all the (non-zero) elements of $\boldsymbol{\Pi}$ are identical at $2 \sigma_{\varepsilon}^{2} / \mathrm{C}$. This is clearly restrictive and reflects the covariance structure of model (14), whereby it is assumed that the disturbances have a constant variance across different levels of remuneration. In the next section we formulate a more general statistical model of the PP matrix with in a multivariate framework that relaxes these assumptions. ${ }^{5}$

\footnotetext{
${ }^{5}$ In the executive compensation literature, pay is usually found to be strongly related to the size of the organisation. The Appendix also shows that if we add to the right-hand side of model (14) a size variable, the least-squares estimators of the dummy-variable coefficients are unchanged.
} 


\section{A Multivariate Approach}

Let $\mathbf{p}_{\mathrm{c}}=\left[\mathrm{p}_{1 \mathrm{c}}, \ldots, \mathrm{p}_{\mathrm{nc}}\right]^{\prime}$ denote the vector of remuneration at institution $\mathrm{c}(\mathrm{c}=1, \ldots, \mathrm{C})$. Define the mean vector and corresponding covariance matrix as

$$
\overline{\mathbf{p}}=\frac{1}{\mathrm{C}} \sum_{\mathrm{c}=1}^{\mathrm{C}} \mathbf{p}_{\mathrm{c}}, \quad \boldsymbol{\Sigma}=\frac{1}{\mathrm{C}} \sum_{\mathrm{c}=1}^{\mathrm{C}}\left(\mathbf{p}_{\mathrm{c}}-\overline{\mathbf{p}}\right)\left(\mathbf{p}_{\mathrm{c}}-\overline{\mathbf{p}}\right)^{\prime} .
$$

If each remuneration vector is independent and has a common covariance matrix, the covariance matrix of the mean vector is

$$
\operatorname{var} \overline{\mathbf{p}}=\frac{1}{\mathrm{C}} \Sigma
$$

To illustrate, we use data on the remuneration of academic executives at 32 Australian universities presented in Table 2. Here, there are $n=5$ levels of remuneration, and universities are ranked according to revenue (given in the last column of the table). Column 2 of Table 3 contains the mean vector (19) for the quartiles as well as for all 32 universities combined, while the covariance matrices $\boldsymbol{\Sigma}$ are given in columns 59. The standard errors of the means, contained in column 3, are the square roots of the diagonal elements of covariance matrix (20). The diagonal elements of columns 5-9 reveal that the variances differ substantially across different levels. For example, in the first quartile, the variance of remuneration of level 1 (which refers to the Vice-Chancellor) is 7.52 , while that of level 3 is 2.91 (both $\times 100$ ). These variances also differ appreciably across different groups of universities; a stark contrast is between the variance of level 1 in the first quartile, 7.52, and that of the same level in the third quartile, $2.59(\times 100)$. It is also to be noted that within a group, remuneration is quite highly correlated across different levels, especially among levels 2-5 (see columns 10-14 of Table 3). These patterns all point to the restrictive assumptions of the dummy-variable approach, discussed above, as being unlikely to be satisfied in practice.

The $\mathrm{n} \times \mathrm{n}$ pay parity (PP) matrix takes the form $\Pi=\mathbf{p} \mathbf{\imath}^{\prime}-\mathbf{p p}^{\prime}$, which we shall estimate by using the mean vector $\overline{\mathbf{p}}$ :

$$
\hat{\Pi}=\overline{\mathbf{p}} \mathbf{\imath}^{\prime}-\mathbf{\imath} \overline{\mathbf{p}}^{\prime}
$$

Table 4 contains in columns 2-6 the estimated PP matrices. Thus, according to the first row for the first quartile, the $\mathrm{VC}$ earns about 50 percent more than the number two academic executive on average, 62 percent more than number three, 75 percent more than number four and 79 percent more than number five. According to the standard errors (to be discussed further below), all these differences are highly significant. Many of the individual elements of the PP matrices differ across groups of universities; below we consider whether or not these differences are statistically significant. Finally, denoting the $(i, j)^{\text {th }}$ element of $\hat{\Pi}$ by $\hat{\pi}_{\mathrm{ij}}$, column 7 of Table 4 contains the row averages of the PP matrix, $\hat{\pi}_{\mathrm{i}}=(1 / 5) \sum_{\mathrm{j}=1}^{5} \hat{\pi}_{\mathrm{ij}}$, which are interpreted as the differences between the respective remuneration levels and the mean. Thus, for the first quartile, VCs 
earn about 53 percent more than the group average, while remuneration of the lower levels is 3, $-9,-21$ and -26 percent away from average. These differences are mostly statistically significant.

The standard errors of the estimated PP matrices are obtained as follows. From equation (21), the $\mathrm{i}^{\text {th }}$ column of $\hat{\boldsymbol{\Pi}}$ is $\hat{\boldsymbol{\pi}}_{\mathrm{i}}=\overline{\mathbf{p}}-\overline{\mathrm{p}}_{\mathrm{i}} \mathbf{l}$, where $\overline{\mathrm{p}}_{\mathrm{i}}$ is the $\mathrm{i}^{\text {th }}$ element of $\overline{\mathbf{p}}$. Define $\mathbf{t}_{\mathrm{i}}$ as the n-vector with $\mathrm{i}^{\text {th }}$ element one and zeros elsewhere, so that $\overline{\mathrm{p}}_{\mathrm{i}}=\mathbf{l}_{\mathrm{i}}^{\prime} \overline{\mathbf{p}}, \overline{\mathrm{p}}_{\mathrm{i}} \mathbf{l}=\mathbf{l}_{\mathrm{i}}^{\prime} \overline{\mathbf{p}} \mathbf{\imath}=\mathbf{\mathbf { l }} \mathbf{l}_{\mathrm{i}}^{\prime} \overline{\mathbf{p}}$ and $\hat{\boldsymbol{\pi}}_{\mathrm{i}}=\left(\mathbf{I}-\mathbf{l} \mathbf{l}_{\mathrm{i}}^{\prime}\right) \overline{\mathbf{p}}$, where $\mathbf{I}$ is the identity matrix. Thus, we can write

$$
\hat{\boldsymbol{\pi}}_{\mathrm{i}}=\mathbf{A}_{\mathrm{i}} \overline{\mathbf{p}}
$$

where $\mathbf{A}_{\mathrm{i}}=\mathbf{I}-\mathbf{l} \mathbf{l}_{\mathrm{i}}^{\prime}$ is an $\mathrm{n} \times \mathrm{n}$ matrix. Equation (22) then implies that $\operatorname{var} \hat{\boldsymbol{\pi}}_{\mathrm{i}}=\mathbf{A}_{\mathrm{i}} \operatorname{var} \overline{\mathbf{p}} \mathbf{A}_{\mathrm{i}}^{\prime}$ or in view of equation (20),

$$
\operatorname{var} \hat{\boldsymbol{\pi}}_{\mathrm{i}}=\frac{1}{\mathrm{C}} \mathbf{A}_{\mathrm{i}} \boldsymbol{\Sigma} \mathbf{A}_{\mathrm{i}}^{\prime}
$$

We illustrate the workings of equation (23) first with the data pertaining to the first quartile universities. Columns 4-8 of Panel A of Table 5 contain the upper triangle of covariance matrix (23) for the first column of the PP matrix, that is, for $\mathrm{i}=1$. The square roots of the diagonal elements of this matrix are the standard errors of the elements of $\hat{\boldsymbol{\pi}}_{\mathrm{i}}$, which are contained in column 3 of Table 5 . For convenience, the point estimate of $\hat{\boldsymbol{\pi}}_{\mathrm{i}}$ is reproduced (from Table 4) in column 2 of Table 5. The subsequent panels of Table 5 contain the corresponding measures for the remaining columns of $\hat{\Pi}$. Taken as a whole, columns 2 and 3 of Table 5 are a vectorised version of the point estimates of the PP matrix and the standard errors contained in Panel A of Table 4 . The standard errors of $\hat{\Pi}$ for the other groups of universities in Table 4 are computed in exactly the same manner.

Write the $n \times 1$ vector of row averages of the PP matrix as $\hat{\bar{\pi}}=(1 / 5) \hat{\boldsymbol{\pi}} \mathbf{\imath}$ $=(1 / 5)\left(\overline{\mathbf{p}} \mathbf{\imath}^{\prime}-\mathbf{\imath} \overline{\mathbf{p}}^{\prime}\right) \mathbf{\imath}=\overline{\mathbf{p}}-(1 / 5) \mathbf{\imath} \mathbf{\imath}^{\prime} \overline{\mathbf{p}}$, or

$$
\hat{\overline{\boldsymbol{\pi}}}=\mathbf{M} \overline{\mathbf{p}},
$$

where $\mathbf{M}=\mathbf{I}-(1 / 5) \mathbf{l}^{\prime}$. Thus from equation (20),

$$
\operatorname{var} \hat{\bar{\pi}}=\frac{1}{\mathrm{C}} \mathbf{M} \Sigma \mathbf{M}^{\prime}
$$

Columns 4-8 of Table 6 contain covariance matrix (25) for the first quartile, column 3 the corresponding standard errors (the square roots of the diagonal elements of the covariance matrix) and column 2 the point estimates of the row averages (reproduced from column 7 of Table 4).

Among the four groups of universities, we can test for differences in the pay parity matrices. Going back to Table 4 , the parity between levels 2 and 4 is $\hat{\pi}_{24}=24.85$ for the first quartile, with standard error 4.51 (both $\times 100$ ). For the second quartile, $\hat{\pi}_{24}=10.28$ with standard error 3.39 . The between-quartile difference $24.85-10.28=14.56$ is given as element $(2,4)$ of the matrix on the left of Panel A of Table 7 . 
Under independence, the standard error of this difference is $\sqrt{4.51^{2}+3.39^{2}}=5.65(\times 100)$, as shown in the corresponding element of the middle matrix of Panel A of Table 7, while the t-value of $14.56 / 5.65=2.58$ is given as element $(2,4)$ of the matrix on the right of the panel. This difference is significant at conventional levels. The other differences in the PPs are similarly interpreted.

\section{8. $\underline{\text { Concluding Comments }}$}

In this paper, we introduced a new tool -- the pay parity (PP) matrix -- for measuring relative pay within organisations and demonstrated its advantages and useful properties. We established how the whole remuneration schedule can be conveniently characterised with the PP matrix and illustrated its application by using data on the remuneration of academic executives.

Important dimensions of the pay schedule are their average gradient and smoothness. These describe how remuneration increases as we move to higher levels in the organisation -- the steeper the gradient, the larger the increment in remuneration. In relatively flat organisational structures, we would expect the schedule to be reasonably smooth and the gradient to be modest, so that there would be little differentiation across various levels. In other types of organisations there could be large jumps in pay, in going from the second to the top job for example, so the remuneration schedule would be steeper and rougher. The pay parity matrix allows us to conveniently measure, and draw inferences about, the gradient and the degree of smoothness.

Among the several other possible applications of the pay parity matrix, the measurement of income inequality is worth singling out. The income of each individual in a country could be compared with that of all others by using a type of parity matrix, but the large dimension of the matrix would be unwieldy. To keep things manageable, suppose individuals are grouped according to income such as quintiles, so that PP matrix is dimensioned $5 \times 5$. As it can be shown that the PP matrix is consistent in aggregation, the $5 \times 5$ matrix and the associated dispersion measures contain much of the population information. For example, the logarithmic variance of income over the whole population is the sum of two unique, nonnegative components, (i) a weighted average of the corresponding group variances, and (ii) a weighted between-group variance. 


\section{APPENDIX}

We consider the nature of the least-squares estimates of model (14), reproduced here:

$$
\mathrm{p}_{\mathrm{ic}}=\alpha+\sum_{\mathrm{j}=2}^{\mathrm{n}} \beta_{\mathrm{j}} \mathrm{d}_{\mathrm{jic}}+\varepsilon_{\mathrm{ic}}, \quad \mathrm{i}=1, \ldots, \mathrm{n} \text { levels, } \quad \mathrm{c}=1, \ldots, \mathrm{C} \text { companies. }
$$

Denote the total number of observations $n \times C$ by $M$. Define the $M \times 1$ column vector of remuneration and corresponding $\mathrm{M} \times(\mathrm{n}+1)$ vector of right-hand side "variables" of model (A1) as

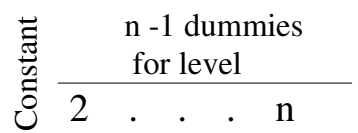

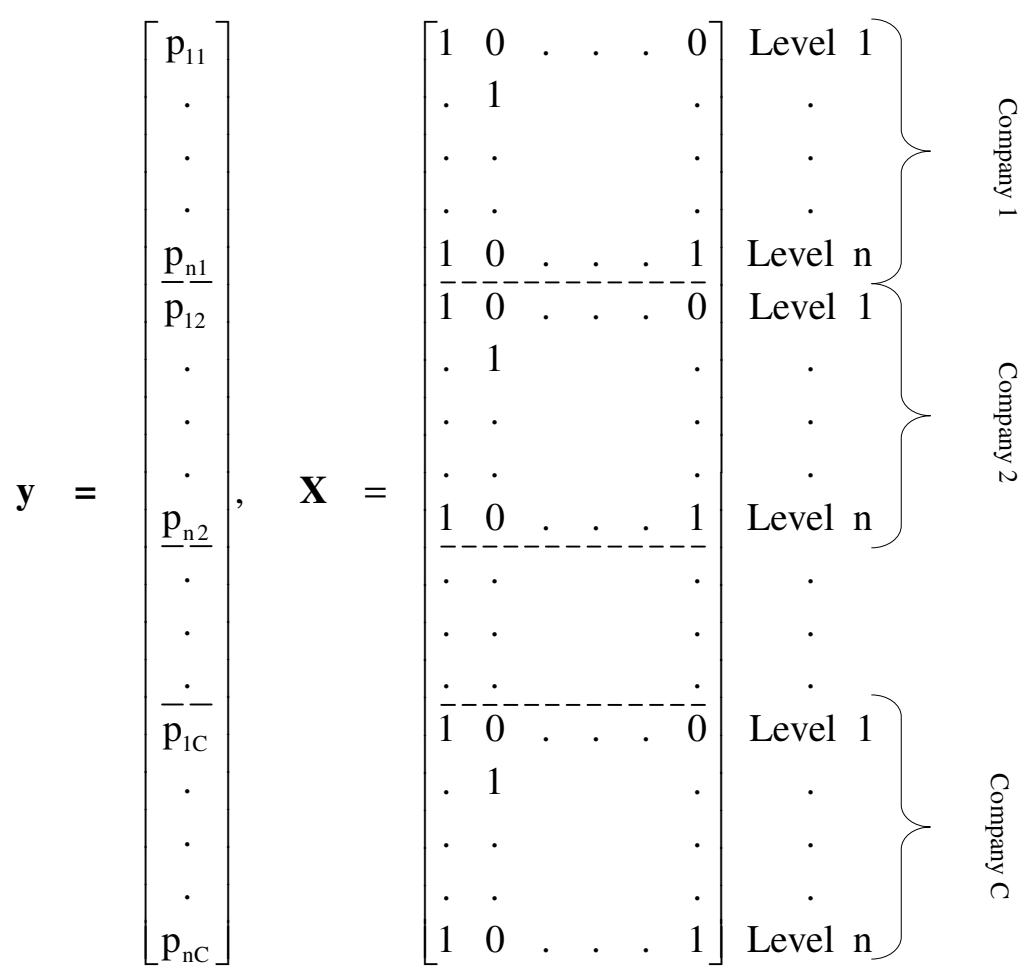

Note that the $\mathbf{X}$ matrix comprises exclusively zeros and ones, which we write as $\mathbf{X}=\left[\begin{array}{l|l}\mathbf{l} & \mathbf{d}_{2} \ldots \mathbf{d}_{\mathrm{n}}\end{array}\right]$, where $\mathbf{l}$ is a column vector of $\mathrm{M}$ elements and $\mathbf{d}_{\mathrm{j}}$ is an $\mathrm{M}$-vector of observations on the $\mathrm{j}^{\text {th }}$ dummy variable. Note also that the inner product of each vector of dummies is equal to the number of companies in the sample and that these vectors are pairwise orthogonal:

$$
\mathbf{d}_{\mathrm{j}}^{\prime} \mathbf{d}_{\mathrm{j}}=\mathrm{C}, \quad \mathrm{j}=2, \ldots, \mathrm{n}, \quad \mathbf{d}_{\mathrm{j}}^{\prime} \mathbf{d}_{\mathrm{k}}=0, \quad \mathrm{j} \neq \mathrm{k} .
$$

Using the above notation, model (A1) can be written for $\mathrm{i}=1, \ldots, \mathrm{n}$ and $\mathrm{c}=1, \ldots, \mathrm{C}$ in vector format as $\mathbf{y}=\mathbf{X} \boldsymbol{\theta}+\boldsymbol{\varepsilon}$, where $\boldsymbol{\theta}=\left[\alpha_{1} \beta_{2} \ldots \beta_{n}\right]^{\prime}$ is a vector of $\mathrm{n}$ coefficients and $\boldsymbol{\varepsilon}$ is a vector of disturbances. The least-squares (LS) estimator of $\boldsymbol{\theta}$ is $\left(\mathbf{X}^{\prime} \mathbf{X}\right)^{-1} \mathbf{X}^{\prime} \mathbf{y}$. The moment matrix takes the form 


$$
\mathbf{X}^{\prime} \mathbf{X}=\mathrm{C}\left[\begin{array}{c:c}
\mathrm{n} & \mathbf{l}^{\prime} \\
\hdashline \mathbf{l} & \mathbf{I}
\end{array}\right],
$$

where $\mathbf{I}$ is a vector of $\mathbf{n}-1$ unit elements and $\mathbf{I}$ is an identity matrix of order $\mathrm{n}-1$. The inverse of this matrix is

$$
\left(\mathbf{X}^{\prime} \mathbf{X}\right)^{-1}=\frac{1}{\mathrm{C}}\left[\begin{array}{c:c}
1 & -\mathbf{l}^{\prime} \\
\hdashline-\mathbf{l} & \mathbf{I}+\mathbf{l l}^{\prime}
\end{array}\right]
$$

The cross-product vector takes the form

$$
\mathbf{X}^{\prime} \mathbf{y}=\left[\begin{array}{c}
\mathrm{p}_{\bullet \bullet} \\
\overline{\mathrm{p}}_{2 \bullet}^{-} \\
\vdots \\
\mathrm{p}_{\mathrm{n}} \bullet
\end{array}\right]
$$

where $\mathrm{p}_{\boldsymbol{~} .}=\sum_{\mathrm{i}=1}^{\mathrm{n}} \sum_{\mathrm{c}=1}^{\mathrm{C}} \mathrm{p}_{\mathrm{ic}}$ and $\mathrm{p}_{\mathrm{j} \boldsymbol{}}=\sum_{\mathrm{c}=1}^{\mathrm{C}} \mathrm{p}_{\mathrm{jc}}$.

Equations (A2) and (A3) imply that the LS estimator of the coefficient vector is

$$
\hat{\boldsymbol{\theta}}=\left[\begin{array}{c}
\hat{\alpha} \\
\hat{\beta}_{2}^{-} \\
\vdots \\
\hat{\beta}_{\mathrm{n}}
\end{array}\right]=\frac{1}{\mathrm{C}}\left[\begin{array}{c:c}
1 & -\mathbf{l}^{\prime} \\
\hdashline-\mathbf{l} & \mathbf{I}+\mathbf{l}^{\prime}
\end{array}\right]\left[\begin{array}{c}
\mathrm{p}_{. \bullet} \\
\mathrm{p}_{2 \bullet} \\
\vdots \\
\mathrm{p}_{\mathrm{n} \bullet}
\end{array}\right]=\frac{1}{\mathrm{C}}\left[\begin{array}{c}
\mathrm{p}_{\bullet \bullet}-\sum_{\mathrm{k}=2}^{\mathrm{n}} \mathrm{p}_{\mathrm{k}} \\
\hdashline-\mathrm{p}_{. \bullet} \mathbf{l}+\left[\begin{array}{c}
\mathrm{p}_{2 \bullet \bullet} \\
\vdots \\
\mathrm{p}_{\mathrm{n} \bullet}
\end{array}\right]+\mathbf{l} \sum_{\mathrm{k}=2}^{\mathrm{n}} \mathrm{p}_{\mathrm{k} \bullet}
\end{array}\right] .
$$

As

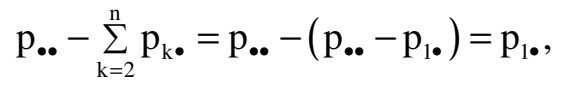

we have

$$
\hat{\alpha}=\frac{1}{C} p_{1}, \quad \hat{\beta}_{j}=\frac{1}{C}\left(p_{j \bullet}-p_{1}\right), \quad j=2, \ldots, n .
$$

In words, the LS estimator of the intercept of model (A1) is the geometric mean of remuneration of level 1. The coefficient of the $\mathrm{j}^{\text {th }}$ dummy is the mean of the difference between the remuneration of level $\mathrm{j}$ and that of level 1.

As the covariance matrix of the LS estimator is $\sigma_{\varepsilon}^{2}\left(\mathbf{X}^{\prime} \mathbf{X}\right)^{-1}$, where $\sigma_{\varepsilon}^{2}$ is the variance of $\varepsilon_{\mathrm{ic}}$, the disturbance term in model (A1), it follows from equation (A2) that

$$
\operatorname{var} \hat{\alpha}=\frac{\sigma_{\varepsilon}^{2}}{C}, \quad \operatorname{var} \hat{\beta}_{j}=\frac{2 \sigma_{\varepsilon}^{2}}{C}, \quad j=2, \ldots, n .
$$

In words, the variances of each of the n-1 coefficients of the dummies take the same value, and this value is twice that of the variance of the intercept. Equation (A5) is equation (17) of the text.

Equation (16) of the text shows that the estimate of the $(i, j)^{\text {th }}$ element of the pay parity matrix is the difference between the $i^{\text {th }}$ and $j^{\text {th }}$ dummy coefficients: 


$$
\hat{\pi}_{i j}=\hat{\beta}_{i}-\hat{\beta}_{j}, \quad i, j=1, \ldots, n, \text { with } \hat{\beta}_{1}=0 .
$$

To derive the corresponding variance, define an $n$-vector that has the value one as element $i+1$ and minus one as element $\mathrm{j}+1$ :

which satisfies

$$
\mathbf{z}=\left[\begin{array}{lllllllllll}
0 & \ldots & 0 & 1 & 0 & \ldots & 0 & -1 & 0 & \ldots & 0
\end{array}\right]^{\prime},
$$

$$
\mathbf{I}^{\prime} \mathbf{z}=0, \quad \mathbf{z}^{\prime} \mathbf{z}=2 .
$$

As $\hat{\pi}_{\mathrm{ij}}=\mathbf{z} \hat{\mathbf{\theta}}$, var $\hat{\pi}_{\mathrm{ij}}=\mathbf{z}^{\prime} \operatorname{var} \hat{\boldsymbol{\theta}} \mathbf{z}=\sigma_{\varepsilon}^{2} \mathbf{z}^{\prime}\left(\mathbf{X}^{\prime} \mathbf{X}\right)^{-1} \mathbf{z}$. It then follows from equation (A2) that

$$
\operatorname{var} \hat{\pi}_{\mathrm{ij}}=\frac{\sigma_{\varepsilon}^{2}}{\mathrm{C}} \mathbf{z}^{\prime}\left[\begin{array}{c:c}
1 & -\mathbf{l}^{\prime} \\
\hdashline-\mathbf{l} & \mathbf{I}+\mathbf{u}^{\prime}
\end{array}\right] \mathbf{z}
$$

Define the vector $\mathbf{z}^{*}$ as $\mathbf{z}$ with the first zero omitted, so that $\mathbf{z}=\left[0, \mathbf{l}_{\mid} \mathbf{z}^{*{ }^{\prime}}\right]^{\prime}$. Constraints (A7) imply that this vector also satisfies

$$
\mathbf{I}^{\prime} \mathbf{z}^{*}=0, \quad \mathbf{z}^{* \prime} \mathbf{z}^{*}=2
$$

The quadratic form on the right-hand side of equation (A8) can then be expressed as

$$
\mathbf{z}^{\prime}\left[\begin{array}{c:c}
1 & -\mathbf{l}^{\prime} \\
\hdashline-\frac{1}{\dagger} & \mathbf{I}+-\mathbf{l}^{\prime}
\end{array}\right] \mathbf{z}=\mathbf{z}^{*^{\prime}}\left(\mathbf{I}+\mathbf{u}^{\prime}\right) \mathbf{z}^{*}=2,
$$

where the last step is based on constraints (A9). This means that

$$
\operatorname{var} \hat{\pi}_{i j}=\frac{2 \sigma_{\varepsilon}^{2}}{C}, \quad i, j=1, \ldots, n, \quad i \neq j .
$$

In words, the sampling variance of each (non-zero) element of the pay parity matrix takes the same value, $2 \sigma_{\varepsilon}^{2} / \mathrm{C}$. This value is the same as the variance of the dummy coefficients given in equation (A5). Equation (A10) is equation (18) of the text.

Another way to derive result (A10) is as follows. As the LS covariance matrix is $\sigma_{\varepsilon}^{2}\left(\mathbf{X}^{\prime} \mathbf{X}\right)^{-1}$, from equation (A2) the covariance matrix of the dummy coefficients is

$$
\frac{\sigma_{\varepsilon}^{2}}{C}\left(\mathbf{I}+\mathbf{u}^{\prime}\right),
$$

so that

$$
\operatorname{cov}\left(\hat{\beta}_{\mathrm{i}}, \hat{\beta}_{\mathrm{j}}\right)=\frac{\sigma_{\varepsilon}^{2}}{\mathrm{C}} .
$$

From equations (A6), (A5) and (A12),

$$
\operatorname{var} \hat{\pi}_{\mathrm{ij}}=\operatorname{var} \hat{\beta}_{\mathrm{i}}+\operatorname{var} \hat{\beta}_{\mathrm{j}}-2 \operatorname{cov}\left(\hat{\beta}_{\mathrm{i}}, \hat{\beta}_{\mathrm{j}}\right)=\frac{2 \sigma_{\varepsilon}^{2}}{\mathrm{C}}+\frac{2 \sigma_{\varepsilon}^{2}}{\mathrm{C}}-\frac{2 \sigma_{\varepsilon}^{2}}{\mathrm{C}}=\frac{2 \sigma_{\varepsilon}^{2}}{\mathrm{C}},
$$


which is the same as result (A10). Note finally that another feature of the pattern of covariance matrix (A11) is that the implied correlation matrix takes the form $(1 / 2)\left(\mathbf{I}+\mathbf{u}^{\prime}\right)$, so that the estimates of the dummy variable coefficients are equicorrelated with correlation one-half.

As prior research has established that executive remuneration systematically increases with the size of the organisation (Murphy, 1999, Soh, 2006), there may be reason to believe that the pay parity matrix is also related to size. If we measure size by revenue, a simple approach to investigate this possibility would be to add the logarithm of total revenue, $r_{c}$, to the right-hand side of model (A1):

$$
\mathrm{p}_{\mathrm{ic}}=\delta+\gamma \mathrm{r}_{\mathrm{c}}+\sum_{\mathrm{j}=2}^{\mathrm{n}} \phi_{\mathrm{j}} \mathrm{d}_{\mathrm{jc}}+\mu_{\mathrm{ic}}
$$

where $\gamma$ is the elasticity of remuneration with respect to size, $\delta$ and $\phi_{\mathrm{j}}$ are new coefficients and $\mu_{\mathrm{ic}}$ is a disturbance term. While the value of the size elasticity in (A13), $\gamma$, is of considerable interest, the sensitivity of remuneration to size is identical for all levels of pay. Accordingly, model (A13) yields exactly the same estimates of the dummy variable coefficients as does (A1); that is to say, the two models imply the same pay parity matrix. We now prove this invariance result.

Proceeding as before, the only difference is that there is now a new second column of $\mathbf{X}$ for revenue. If we write $\mathbf{l}_{\mathrm{n}}$ for a column vector of $\mathrm{n}$ unit elements, this second column can be expressed as

$$
\begin{aligned}
& {\left[\begin{array}{lll:lll:l:lll}
\mathrm{r}_{1} & \ldots & \mathrm{r}_{1} & \mathrm{r}_{2} & \ldots & \mathrm{r}_{2} & \ldots & \mathrm{r}_{\mathrm{C}} & \ldots & \mathrm{r}_{\mathrm{C}}
\end{array}\right]^{\prime} } \\
= & {\left[\begin{array}{llllllll}
\mathrm{r}_{1} \mathbf{l}_{\mathrm{n}}^{\prime} & & \mathrm{r}_{2} \mathbf{l}_{\mathrm{n}}^{\prime} & \ldots & & \mathrm{r}_{\mathrm{C}} \mathbf{l}_{\mathrm{n}}^{\prime}
\end{array}\right]^{\prime}=\mathbf{r} \otimes \mathbf{l}_{\mathrm{n}}, }
\end{aligned}
$$

where $\mathbf{r}=\left[\mathrm{r}_{1}, \ldots, \mathrm{r}_{\mathrm{c}}\right]^{\prime}$ and $\otimes$ is the Kronecker product. Thus, $\mathbf{X}$ can be written as $\mathbf{X}=$ $\left[\begin{array}{l|l:lll}\mathbf{l}_{\mathrm{M}} & \mathbf{r} \otimes \mathbf{l}_{\mathrm{n}} & \mathbf{d}_{2} & \ldots & \mathbf{d}_{\mathrm{n}}\end{array}\right]$, where, as before, $\mathbf{d}_{\mathrm{j}}$ is an M-vector of observations on the $\mathrm{j}^{\text {th }}$ dummy variable. Using the above notation, model (A13) can be written for $\mathrm{i}=1, \ldots, \mathrm{n}$ and $\mathrm{c}=1, \ldots, \mathrm{C}$ in vector format as $\mathbf{y}=\mathbf{X} \boldsymbol{\theta}+\boldsymbol{\mu}$, where $\boldsymbol{\theta}=\left[\begin{array}{lllll}\delta & \gamma & \phi_{2} & \ldots & \phi_{\mathrm{n}}\end{array}\right]^{\prime}$ and $\boldsymbol{\mu}$ is a vector of disturbances.

The least-squares estimator of $\boldsymbol{\theta}$ is $\left(\mathbf{X}^{\prime} \mathbf{X}\right)^{-1} \mathbf{X}^{\prime} \mathbf{y}$. Defining $\mathrm{r}=\sum_{\mathrm{c}=1}^{\mathrm{C}} \mathrm{r}_{\mathrm{c}}$ as total revenue of all $\mathrm{C}$ companies, and $s^{2}=\sum_{c=1}^{C} r_{c}^{2}$ as the sum of squared revenue, the moment matrix takes the form

$$
\mathbf{X}^{\prime} \mathbf{X}=\left[\begin{array}{cc:c}
\mathrm{n}\left[\begin{array}{cc}
\mathrm{C} & \mathrm{r} \\
& \mathrm{s}^{2}
\end{array}\right] & \mathrm{Cl}_{\mathrm{n}-1}^{\prime} \\
\hdashline \mathbf{r l}_{\mathrm{n}-1}^{\prime} \\
\hdashline \mathbf{l}_{\mathrm{n}-1} & \mathrm{rt}_{\mathrm{n}-1} & \mathrm{CI}_{\mathrm{n}-1}
\end{array}\right],
$$

where $\mathbf{I}_{\mathrm{n}-1}$ is an identity matrix of order $(\mathrm{n}-1)$. The inverse of this moment matrix is 
(A14)

$$
\left(\mathbf{X}^{\prime} \mathbf{X}\right)^{-1}=\left[\begin{array}{cc:c}
\frac{1}{\Delta}\left[\begin{array}{cc}
\mathrm{ns}^{2}-\frac{\mathrm{n}-1}{\mathrm{C}} \mathrm{r}^{2} & -\mathrm{r} \\
-\mathrm{r} & \mathrm{C}
\end{array}\right] & -\frac{1}{\mathrm{C}} \mathbf{i}_{\mathrm{n}-1}^{\prime} \\
\hdashline-\frac{1}{\mathrm{C}} \mathbf{i}_{\mathrm{n}-1} & \mathbf{0}_{\mathrm{n}-1}^{\prime} & \frac{1}{\mathrm{C}}\left(\mathbf{I}_{\mathrm{n}-1}+\mathbf{l}_{\mathrm{n}-1} \mathbf{l}_{\mathrm{n}-1}^{\prime}\right)
\end{array}\right],
$$

where $\Delta=\mathrm{C}\left[\mathrm{ns}^{2}-\mathrm{r}^{2}(\mathrm{n}-1) / \mathrm{C}\right]-\mathrm{r}^{2}$ and $\mathbf{0}_{\mathrm{n}-1}$ is an $\mathrm{n}-1$ vector of zeros. The cross-product vector takes the form

$$
\mathbf{X}^{\prime} \mathbf{y}=\left[\begin{array}{c}
\mathrm{p}_{\bullet} \\
\sum_{\mathrm{c}=1}^{\mathrm{c}} \mathrm{r}_{\mathrm{c}} \mathrm{p}_{\bullet \mathrm{c}} \\
\hdashline \mathrm{p}_{2} \cdot \\
\vdots \\
\mathrm{p}_{\mathrm{n}} \cdot
\end{array}\right]
$$

where $\mathrm{p}_{. .}=\sum_{\mathrm{i}=1}^{\mathrm{n}} \sum_{c=1}^{\mathrm{C}} \mathrm{p}_{\mathrm{ic}}, \mathrm{p}_{\boldsymbol{c}}=\sum_{\mathrm{i}=1}^{\mathrm{n}} \mathrm{p}_{\mathrm{ic}}$ and $\mathrm{p}_{\mathrm{j} \bullet}=\sum_{\mathrm{c}=1}^{\mathrm{C}} \mathrm{p}_{\mathrm{jc}}$.

Combining equations (A14) and (A15) yields the following estimator of the vector of the dummy variable coefficients

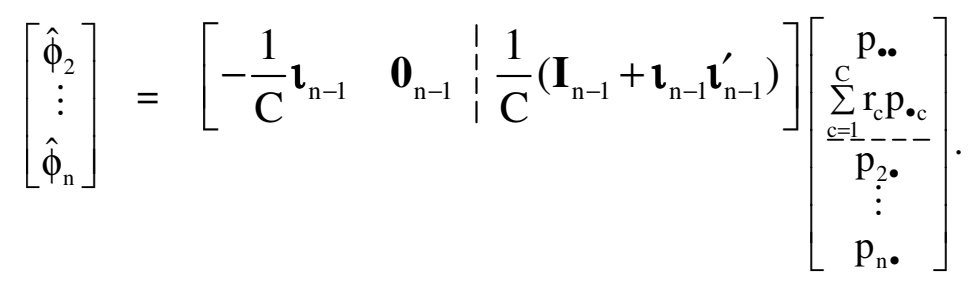

This shows that the $j^{\text {th }}$ coefficient is

$$
\hat{\phi}_{j}=-\frac{1}{C} p_{. .}+\frac{1}{C}\left(p_{j \bullet}+\sum_{k=2}^{n} p_{k} \cdot\right) .
$$

As $\sum_{\mathrm{k}=2}^{\mathrm{n}} \mathrm{p}_{\mathrm{k}}=\mathrm{p}_{. \bullet}-\sum_{\mathrm{c}=1}^{\mathrm{C}} \mathrm{p}_{\mathrm{lc}}=\mathrm{p}_{. .}-\mathrm{p}_{\mathbf{l}}$, the above simplifies to

$$
\hat{\phi}_{\mathrm{j}}=\frac{1}{\mathrm{C}}\left(\mathrm{p}_{\mathrm{j} \bullet}-\mathrm{p}_{\mathrm{1}}\right) .
$$

In words, the coefficient of the $j^{\text {th }}$ dummy is the mean of the difference between the remuneration of level $\mathrm{j}$ and that of level 1 ; or the mean of level $\mathrm{j}$ relative to the mean of level 1 . This is identical to the LS estimator of the corresponding dummy variable coefficient $\beta_{\mathrm{j}}$ in model (A1), given in equation (A4). This establishes that simply adding revenue to the remuneration equation has no impact on the pay parity matrix. 


\section{REFERENCES}

Clements, K. W. and H. Y. Izan (2008). "The Stairway to the Top: The Remuneration of Academic Executives." Australian Journal of Management 33, No. 1: 1-30.

Murphy, K. J. (1999). "Executive Compensation." In O. Ashenfelter and D. Card, eds, Handbook of Labour Economics. Vol. 3, Elsevier Science B. V.

Soh, L. H. C. (2007). “The Market for Vice-Chancellors.” Australian Journal of Management. Vol. 32, No. 1: 29-55. 
FIGURE 1

THREE MEASURES OF RELATIVE PAY

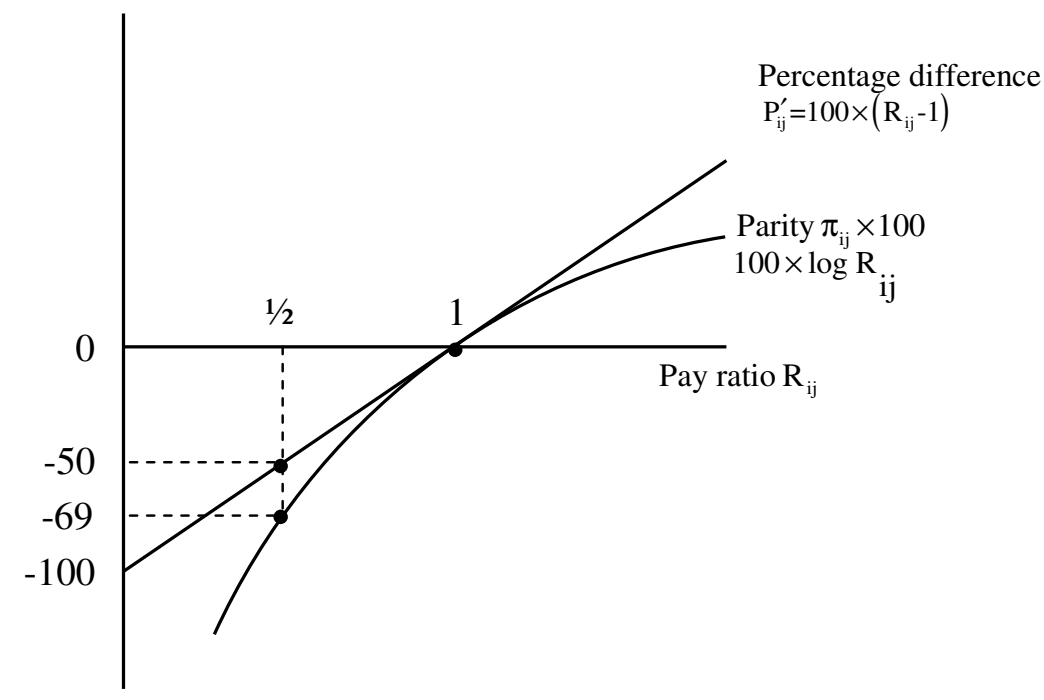

TABLE 1

REMUNERATION SCHEDULE AND PAY PARITY MATRIX, ACADEMIC EXECUTIVES, THE UNIVERSITY OF WESTERN AUSTRALIA, 2005

\begin{tabular}{|c|c|c|c|c|c|c|c|c|c|c|}
\hline \multirow[b]{2}{*}{$\begin{array}{c}\text { Level i } \\
\text { (1) } \\
\end{array}$} & \multicolumn{2}{|c|}{ Remuneration } & \multicolumn{5}{|c|}{$\begin{array}{c}\text { Pay parity matrix } \Pi \\
(\text { Level j) }\end{array}$} & \multicolumn{3}{|c|}{ Summary of PP matrix rows } \\
\hline & $\begin{array}{c}\text { Dollars } \\
\left(\$^{\prime} 000\right) \\
(2)\end{array}$ & $\begin{array}{c}\text { Logs } \\
\text { (3) }\end{array}$ & $\begin{array}{c}1 \\
(4)\end{array}$ & $\begin{array}{c}2 \\
(5)\end{array}$ & $\begin{array}{c}3 \\
(6)\end{array}$ & $\begin{array}{l}4 \\
(7)\end{array}$ & $\begin{array}{c}5 \\
(8)\end{array}$ & $\begin{array}{c}\text { Average } \\
\text { (9) }\end{array}$ & $\begin{array}{c}\text { Average } \\
\text { squared } \\
\text { (10) }\end{array}$ & $\begin{array}{c}\text { Standard } \\
\text { deviation } \\
\text { (11) }\end{array}$ \\
\hline 1 & 485 & 13.0919 & 0.00 & 37.00 & 46.38 & 49.72 & 56.747 & 37.97 & 14.42 & 20.02 \\
\hline 2 & 335 & 12.7219 & -37.00 & 0.00 & 9.38 & 12.72 & 19.74 & 0.97 & 0.01 & 20.02 \\
\hline 3 & 305 & 12.6281 & -46.38 & -9.38 & 0.00 & 3.33 & 10.35 & -8.42 & 0.71 & 20.02 \\
\hline 4 & 295 & 12.5947 & -49.72 & -12.72 & -3.33 & 0.00 & 7.02 & -11.75 & 1.38 & 20.02 \\
\hline 5 & 275 & 12.5245 & -56.74 & -19.74 & -10.35 & -7.02 & 0.00 & -18.77 & 3.52 & 20.02 \\
\hline Mean & 339 & 12.7122 & -37.97 & -0.97 & 8.42 & 11.75 & 18.77 & 0.00 & 4.01 & 20.02 \\
\hline SD & 75.52 & 0.2002 & 20.02 & 20.02 & 20.02 & 20.02 & 20.02 & 20.02 & & \\
\hline
\end{tabular}

Average sum of squares

$\left(1 / 5^{2}\right) \sum_{\mathrm{i}=1}^{5} \sum_{\mathrm{j}=1}^{5} \pi_{\mathrm{ij}}^{2}=0.80 \times 10^{-1}$

Notes: 1. All entries in column 4-11 are to be divided by 100.

2. $\mathrm{SD}=$ standard deviation, defined as the square root of the mean squared deviation of $n$ values $\mathrm{x}_{1}, \ldots, \mathrm{x}_{n}$ from the mean $\overline{\mathrm{x}}$, $\sqrt{(1 / n) \sum_{i=1}^{n}\left(x_{i}-\bar{x}\right)^{2}}$.

Source: The remuneration data of column 2 refer to academic-executives of the University of Western Australia. These data are from the University's Annual Report, 2005, available at http://year2005.annualreport.publishing.uwa.edu.au/welcome. 
FIGURE 2

STEPS AND GRADIENT OF THE REMUNERATION SCHEDULE, ACADEMIC EXECUTIVES, THE UNIVERSITY OF WESTERN AUSTRALIA, 2005

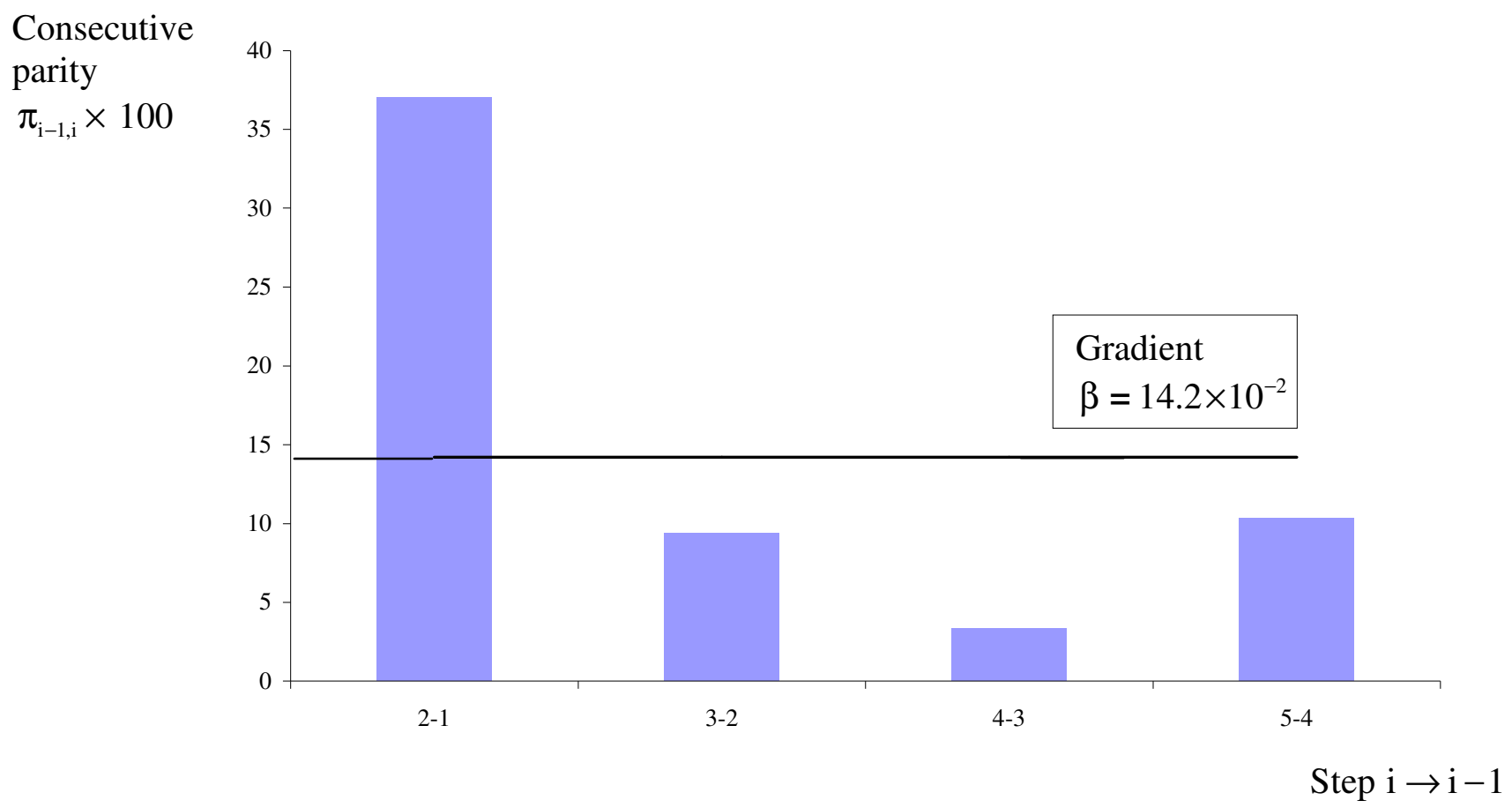


TABLE 2

ACADEMIC EXECUTIVE REMUNERATION AND REVENUE, AUSTRALIAN UNIVERSITIES, 2005

\begin{tabular}{|c|c|c|c|c|c|c|}
\hline \multirow{2}{*}{ University } & \multicolumn{5}{|c|}{ Remuneration at level (\$’00) } & \multirow{2}{*}{$\begin{array}{r}\text { Revenue } \\
\quad(\$ ' m)\end{array}$} \\
\hline & 1 & 2 & 3 & 4 & 5 & \\
\hline \multicolumn{7}{|c|}{ A. First Quartile } \\
\hline 1. USC & 335 & 185 & 175 & 165 & 165 & 51 \\
\hline 2. SCU & 375 & 285 & 225 & 225 & 215 & 110 \\
\hline 3. Canberra & 435 & 335 & 295 & 245 & 235 & 123 \\
\hline 4. Ballarat & 325 & 215 & 205 & 195 & 195 & 133 \\
\hline 5. SQ & 345 & 305 & 215 & 195 & 175 & 153 \\
\hline 6. Murdoch & 405 & 265 & 235 & 235 & 215 & 196 \\
\hline 7. JCU & 345 & 235 & 235 & 185 & 185 & 214 \\
\hline 8. ECU & 795 & 175 & 165 & 115 & 105 & 217 \\
\hline Means & 420 & 250 & 219 & 195 & 186 & 150 \\
\hline \multicolumn{7}{|c|}{ B. Second Quartile } \\
\hline 9. Wollongong & 465 & 315 & 235 & 235 & 235 & 273 \\
\hline 10. Swinburne & 255 & 205 & 205 & 195 & 195 & 275 \\
\hline 11. CQ & 485 & 235 & 225 & 215 & 195 & 276 \\
\hline 12. Tasmania & 365 & 225 & 215 & 215 & 185 & 286 \\
\hline 13. CSU & 325 & 245 & 245 & 225 & 195 & 294 \\
\hline 14. Victoria & 475 & 305 & 305 & 295 & 275 & 328 \\
\hline 15. Newcastle & 445 & 345 & 345 & 275 & 215 & 339 \\
\hline 16. Western Sydney & 515 & 285 & 285 & 285 & 215 & 356 \\
\hline Means & 416 & 270 & 258 & 243 & 214 & 303 \\
\hline \multicolumn{7}{|c|}{ C. Third Quartile } \\
\hline 17. SA & 465 & 295 & 265 & 255 & 235 & 375 \\
\hline 18. LaTrobe & 415 & 365 & 305 & 295 & 295 & 384 \\
\hline 19. Macquarie & 435 & 295 & 285 & 285 & 285 & 391 \\
\hline 20. UTS & 515 & 415 & 315 & 295 & 255 & 412 \\
\hline 21. Griffith & 335 & 315 & 305 & 295 & 245 & 432 \\
\hline 22. Deakin & 515 & 355 & 295 & 275 & 265 & 436 \\
\hline 23. Curtin & 475 & 215 & 175 & 165 & 165 & 442 \\
\hline 24. Adelaide & 595 & 425 & 285 & 265 & 255 & 477 \\
\hline Means & 469 & 335 & 279 & 266 & 250 & 419 \\
\hline \multicolumn{7}{|c|}{ D. Fourth Quartile } \\
\hline 25. UWA & 485 & 335 & 305 & 295 & 275 & 509 \\
\hline 26. RMIT & 435 & 375 & 315 & 315 & 255 & 591 \\
\hline 27. ANU & 558 & 303 & 288 & 288 & 258 & 608 \\
\hline 28. NSW & 605 & 385 & 245 & 225 & 215 & 775 \\
\hline 29. Queensland & 955 & 525 & 395 & 365 & 345 & 913 \\
\hline 30. Sydney & 575 & 485 & 375 & 365 & 345 & 1,022 \\
\hline 31. Monash & 615 & 575 & 565 & 465 & 455 & 1,041 \\
\hline 32. Melbourne & 855 & 605 & 605 & 525 & 265 & 1,212 \\
\hline Means & 635 & 448 & 387 & 355 & 302 & 834 \\
\hline Grand Mean & 485 & 326 & 285 & 265 & 238 & 426 \\
\hline
\end{tabular}


TABLE 3

ACADEMIC EXECUTIVE REMUNERATION, MEANS, COVARIANCES AND CORRELATIONS, AUSTRALIAN UNIVERSITIES, 2005

\begin{tabular}{|c|c|c|c|c|c|c|c|c|c|c|c|c|c|}
\hline \multirow[b]{2}{*}{ Level } & \multicolumn{3}{|c|}{ Geometric Mean } & \multicolumn{5}{|c|}{$\begin{array}{c}\text { Covariance matrix } \\
\text { (Level) }\end{array}$} & \multicolumn{5}{|c|}{$\begin{array}{c}\text { Correlation matrix } \\
\text { (Level) }\end{array}$} \\
\hline & Logarithmic & $\begin{array}{l}\text { Standard } \\
\text { Error }\end{array}$ & $\begin{array}{c}\text { Dollars } \\
\left({ }^{\prime} 000\right)\end{array}$ & 1 & 2 & 3 & 4 & 5 & 1 & 2 & 3 & 4 & 5 \\
\hline (1) & (2) & (3) & (4) & (5) & (6) & (7) & (8) & (9) & (10) & (11) & (12) & (13) & (14) \\
\hline \multicolumn{14}{|c|}{ A. First Quartile } \\
\hline 1 & 5.9962 & 0.0969 & 402 & 7.516 & -2.035 & -1.550 & -3.902 & -4.482 & 1.000 & -0.338 & -0.331 & -0.627 & -0.697 \\
\hline 2 & 5.4978 & 0.0776 & 244 & & 4.822 & 3.279 & 4.173 & 3.907 & & 1.000 & 0.876 & 0.837 & 0.759 \\
\hline 3 & 5.3733 & 0.0603 & 216 & & & 2.908 & 3.316 & 3.340 & & & 1.000 & 0.857 & 0.836 \\
\hline 4 & 5.2493 & 0.0803 & 190 & & & & 5.155 & 5.237 & & & & 1.000 & 0.984 \\
\hline 5 & 5.2024 & 0.0829 & 182 & & & & & 5.495 & & & & & 1.000 \\
\hline \multicolumn{14}{|c|}{ B. Second Quartile } \\
\hline 1 & 6.0071 & 0.0807 & 406 & 5.210 & 2.749 & 2.219 & 2.325 & 1.457 & 1.000 & 0.699 & 0.566 & 0.714 & 0.525 \\
\hline 2 & 5.5836 & 0.0609 & 266 & & 2.971 & 2.515 & 2.042 & 1.493 & & 1.000 & 0.849 & 0.831 & 0.713 \\
\hline 3 & 5.5359 & 0.0608 & 254 & & & 2.953 & 2.242 & 1.241 & & & 1.000 & 0.915 & 0.594 \\
\hline 4 & 5.4808 & 0.0504 & 240 & & & & 2.032 & 1.285 & & & & 1.000 & 0.741 \\
\hline 5 & 5.3571 & 0.0430 & 212 & & & & & 1.478 & & & & & 1.000 \\
\hline \multicolumn{14}{|c|}{ C. Third Quartile } \\
\hline 1 & 6.1375 & 0.0568 & 463 & 2.585 & 1.190 & -0.349 & -0.599 & -0.217 & 1.000 & 0.358 & -0.122 & -0.204 & -0.081 \\
\hline 2 & 5.7937 & 0.0732 & 328 & & 4.283 & 3.059 & 2.898 & 2.514 & & 1.000 & 0.831 & 0.767 & 0.726 \\
\hline 3 & 5.6162 & 0.0629 & 275 & & & 3.163 & 3.219 & 2.716 & & & 1.000 & 0.992 & 0.912 \\
\hline 4 & 5.5696 & 0.0645 & 262 & & & & 3.329 & 2.845 & & & & 1.000 & 0.931 \\
\hline 5 & 5.5086 & 0.0592 & 247 & & & & & 2.804 & & & & & 1.000 \\
\hline \multicolumn{14}{|c|}{ D. Fourth Quartile } \\
\hline 1 & 6.4222 & 0.0877 & 615 & 6.160 & 4.184 & 4.033 & 3.158 & 1.355 & 1.000 & 0.696 & 0.541 & 0.499 & 0.247 \\
\hline 2 & 6.0769 & 0.0857 & 436 & & 5.872 & 6.368 & 5.131 & 3.239 & & 1.000 & 0.875 & 0.831 & 0.603 \\
\hline 3 & 5.9106 & 0.1062 & 369 & & & 9.017 & 7.544 & 4.299 & & & 1.000 & 0.986 & 0.647 \\
\hline 4 & 5.8405 & 0.0901 & 344 & & & & 6.497 & 3.569 & & & & 1.000 & 0.632 \\
\hline 5 & 5.6836 & 0.0783 & 294 & & & & & 4.905 & & & & & 1.000 \\
\hline \multicolumn{14}{|c|}{ E. All } \\
\hline 1 & 6.1408 & 0.0510 & 464 & 8.318 & 5.286 & 4.306 & 3.606 & 2.373 & 1.000 & 0.595 & 0.518 & 0.423 & 0.314 \\
\hline 2 & 5.7380 & 0.0544 & 310 & & 9.475 & 8.068 & 8.123 & 6.695 & & 1.000 & 0.909 & 0.893 & 0.831 \\
\hline 3 & 5.6090 & 0.0510 & 273 & & & 8.308 & 8.173 & 6.300 & & & 1.000 & 0.960 & 0.835 \\
\hline 4 & 5.5350 & 0.0522 & 253 & & & & 8.731 & 6.964 & & & & 1.000 & 0.900 \\
\hline 5 & 5.4379 & 0.0463 & 230 & & & & & 6.854 & & & & & 1.000 \\
\hline
\end{tabular}


TABLE 4

PAY PARITY MATRICES,

ACADEMIC EXECUTIVES, AUSTRALIAN UNIVERSITIES, 2005

(Standard errors in parentheses)

\begin{tabular}{|c|c|c|c|c|c|c|}
\hline \multirow{2}{*}{ Level } & \multicolumn{5}{|c|}{ Levels } & \multirow{3}{*}{$\begin{array}{c}\text { Row } \\
\text { Average } \\
(7)\end{array}$} \\
\hline & \multirow[b]{2}{*}{ (2) } & \multirow{2}{*}{$\begin{array}{l}2 \\
\text { (3) } \\
\end{array}$} & \multirow{2}{*}{$\begin{array}{l}3 \\
\text { (4) } \\
\end{array}$} & \multirow{2}{*}{$\begin{array}{r}4 \\
(5) \\
\end{array}$} & \multirow{2}{*}{$\begin{array}{l}5 \\
\text { (6) } \\
\end{array}$} & \\
\hline (1) & & & & & & \\
\hline \multicolumn{7}{|c|}{ A. First Quartile } \\
\hline 1 & 0.00 & $49.84(14.32)$ & $62.29(13.00)$ & $74.69(16.00)$ & $79.38(16.57)$ & $53.24(11.85)$ \\
\hline 2 & $-49.84(14.32)$ & 0.00 & $12.44(3.83)$ & $24.85(4.51)$ & $29.54(5.59)$ & $3.40(3.71)$ \\
\hline 3 & $-62.29(13.00)$ & $-12.44(3.83)$ & 0.00 & $12.41(4.23)$ & $17.10(4.64)$ & $-9.05 \quad(2.03)$ \\
\hline 4 & $-74.69(16.00)$ & $-24.85(4.51)$ & $-12.41(4.23)$ & 0.00 & $4.70(1.48)$ & $-21.45 \quad(4.33)$ \\
\hline 5 & $-79.38(16.57)$ & $-29.54(5.59)$ & $-17.10(4.64)$ & $-4.70(1.48)$ & 0.00 & $-26.14 \quad(5.04)$ \\
\hline \multicolumn{7}{|c|}{ B. Second Quartile } \\
\hline 1 & 0.00 & 42.35 (5.79) & $47.12(6.82)$ & $52.63(5.69)$ & $65.00(6.87)$ & $41.42(4.71)$ \\
\hline 2 & $-42.35(5.79)$ & 0.00 & $4.77(3.34)$ & $10.28(3.39)$ & $22.65(4.28)$ & $-0.93(2.28)$ \\
\hline 3 & $-47.12(6.82)$ & $-4.77(3.34)$ & 0.00 & $5.51(2.50)$ & 17.87 (4.94) & $-5.70(2.82)$ \\
\hline 4 & $-52.63(5.69)$ & $-10.28(3.39)$ & $-5.51(2.50)$ & 0.00 & $12.37(3.43)$ & $-11.21(1.63)$ \\
\hline 5 & $-65.00(6.87)$ & $-22.65(4.28)$ & $-17.87(4.94)$ & $-12.37(3.43)$ & 0.00 & $-23.58(3.25)$ \\
\hline \multicolumn{7}{|c|}{ C. Third Quartile } \\
\hline 1 & 0.00 & 34.38 (7.49) & $52.13(8.98)$ & $56.79(9.43)$ & $62.89(8.53)$ & $41.24(6.68)$ \\
\hline 2 & $-34.38(7.49)$ & 0.00 & $17.75(4.08)$ & $22.41(4.77)$ & $28.51(5.07)$ & $6.86(3.03)$ \\
\hline 3 & $-52.13(8.98)$ & $-17.75(4.08)$ & 0.00 & $4.66(0.82)$ & $10.76(2.59)$ & $-10.89(2.42)$ \\
\hline 4 & $-56.79(9.43)$ & $-22.41(4.77)$ & $-4.66(0.82)$ & 0.00 & $6.11(2.35)$ & $-15.55(2.92)$ \\
\hline 5 & $-62.89(8.53)$ & $-28.51(5.07)$ & $-10.76(2.59)$ & $-6.11(2.35)$ & 0.00 & $-21.66(2.66)$ \\
\hline
\end{tabular}

(Continued on next page) 
TABLE 4 (Continued)

PAY PARITY MATRICES,

ACADEMIC EXECUTIVES, AUSTRALIAN UNIVERSITIES, 2005

(Standard errors in parentheses)

\begin{tabular}{|c|c|c|c|c|c|c|}
\hline \multirow{2}{*}{ Level } & \multicolumn{5}{|c|}{ Levels } & \multirow{3}{*}{$\begin{array}{c}\text { Row } \\
\text { Average } \\
\text { (7) }\end{array}$} \\
\hline & 1 & & 3 & & & \\
\hline (1) & (2) & (3) & (4) & (5) & (6) & \\
\hline \multicolumn{7}{|c|}{ D. Fourth Quartile } \\
\hline 1 & 0.00 & $34.53(6.77)$ & $51.16(9.43)$ & $58.18(8.90)$ & $73.86(10.22)$ & $43.55(6.45)$ \\
\hline 2 & $-34.53 \quad(6.77)$ & 0.00 & $16.63(5.19)$ & $23.64(5.13)$ & $39.33 \quad(7.33)$ & $9.01 \quad(2.92)$ \\
\hline 3 & $-51.16(9.43)$ & $-16.63(5.19)$ & 0.00 & $7.01 \quad(2.31)$ & $22.70(8.16)$ & $-7.61(3.94)$ \\
\hline 4 & $-58.18(8.90)$ & $-23.64(5.13)$ & $-7.01(2.31)$ & 0.00 & $15.69(7.30)$ & $-14.63(3.29)$ \\
\hline 5 & $-73.86(10.22)$ & $-39.33(7.33)$ & $-22.70(8.16)$ & $-15.69(7.30)$ & 0.00 & $-30.32(5.79)$ \\
\hline \multicolumn{7}{|c|}{ E. All } \\
\hline 1 & 0.00 & $40.28(4.75)$ & $53.17(5.00)$ & $60.57(5.54)$ & $70.28(5.71)$ & 44.86 (4.04) \\
\hline 2 & $-40.28(4.75)$ & 0.00 & $12.90(2.27)$ & $20.29(2.48)$ & $30.01(3.03)$ & $4.58(1.65)$ \\
\hline 3 & $-53.17(5.00)$ & $-12.90(2.27)$ & 0.00 & 7.40 (1.47) & $17.11(2.83)$ & $-8.31(1.48)$ \\
\hline 4 & $-60.57(5.54)$ & $-20.29(2.48)$ & $-7.40(1.47)$ & 0.00 & $9.71(2.28)$ & $-15.71(1.72)$ \\
\hline 5 & $-70.28(5.71)$ & $-30.01(3.03)$ & $-17.11(2.83)$ & $-9.71(2.28)$ & 0.00 & $-25.42(2.26)$ \\
\hline
\end{tabular}


TABLE 5

COLUMNS OF PAY PARITY MATRIX AND COVARIANCE MATRICES, ACADEMIC EXECUTIVES, AUSTRALIAN UNIVERSITIES, 2005, FIRST QUARTILE

\begin{tabular}{|c|c|c|c|c|c|c|c|}
\hline \multirow[b]{2}{*}{ Level } & \multicolumn{2}{|c|}{ Column of $\Pi_{\text {matrix }}$} & \multicolumn{5}{|c|}{$\begin{array}{c}\text { Covariance matrix } \\
\text { (Level) }\end{array}$} \\
\hline & $\begin{array}{c}\text { Point } \\
\text { estimate }\end{array}$ & $\begin{array}{l}\text { Standard } \\
\text { error }\end{array}$ & 1 & 2 & 3 & 4 & 5 \\
\hline (1) & (2) & (3) & (4) & (5) & (6) & (7) & (8) \\
\hline \multicolumn{8}{|c|}{ A. Column 1} \\
\hline 1 & 0.000 & 0.000 & 0.000 & 0.000 & 0.000 & 0.000 & 0.000 \\
\hline 2 & -49.844 & 14.322 & & 2.051 & 1.798 & 2.203 & 2.243 \\
\hline 3 & -62.286 & 13.001 & & & 1.690 & 2.036 & 2.111 \\
\hline 4 & -74.692 & 15.998 & & & & 2.560 & 2.642 \\
\hline 5 & -79.383 & 16.574 & & & & & 2.747 \\
\hline \multicolumn{8}{|c|}{ B. Column 2} \\
\hline 1 & 49.844 & 14.322 & 2.051 & 0.000 & 0.254 & -0.152 & -0.191 \\
\hline 2 & 0.000 & 0.000 & & 0.000 & 0.000 & 0.000 & 0.000 \\
\hline 3 & -12.443 & 3.827 & & & 0.146 & 0.086 & 0.122 \\
\hline 4 & -24.848 & 4.515 & & & & 0.204 & 0.247 \\
\hline 5 & -29.539 & 5.593 & & & & & 0.313 \\
\hline \multicolumn{8}{|c|}{ C. Column 3} \\
\hline 1 & 62.286 & 13.001 & 1.690 & -0.107 & 0.000 & -0.345 & -0.421 \\
\hline 2 & 12.443 & 3.827 & & 0.146 & 0.000 & 0.061 & 0.024 \\
\hline 3 & 0.000 & 0.000 & & & 0.000 & 0.000 & 0.000 \\
\hline 4 & -12.406 & 4.228 & & & & 0.179 & 0.186 \\
\hline 5 & -17.096 & 4.639 & & & & & 0.215 \\
\hline \multicolumn{8}{|c|}{ D. Column 4} \\
\hline 1 & 74.692 & 15.998 & 2.560 & 0.356 & 0.524 & 0.000 & -0.083 \\
\hline 2 & 24.848 & 4.515 & & 0.204 & 0.118 & 0.000 & -0.043 \\
\hline 3 & 12.406 & 4.228 & & & 0.179 & 0.000 & -0.007 \\
\hline 4 & 0.000 & 0.000 & & & & 0.000 & 0.000 \\
\hline 5 & -4.691 & 1.484 & & & & & 0.022 \\
\hline \multicolumn{8}{|c|}{ E. Column 5} \\
\hline 1 & 79.383 & 16.574 & 2.747 & 0.504 & 0.636 & 0.105 & 0.000 \\
\hline 2 & 29.539 & 5.593 & & 0.313 & 0.191 & 0.066 & 0.000 \\
\hline 3 & 17.096 & 4.639 & & & 0.215 & 0.029 & 0.000 \\
\hline 4 & 4.691 & 1.484 & & & & 0.022 & 0.000 \\
\hline 5 & 0.000 & 0.000 & & & & & 0.000 \\
\hline
\end{tabular}

Note: All entries are to be divided by 100 . 
TABLE 6

DEVIATIONS FROM MEAN REMUNERATION AND COVARIANCE MATRIX, ACADEMIC EXECUTIVES, AUSTRALIAN UNIVERSITIES, 2005, FIRST QUARTILE

\begin{tabular}{ccccccccc}
\hline \hline & \multicolumn{2}{c}{ Deviation from mean } & & \multicolumn{5}{c}{$\begin{array}{c}\text { Covariance matrix } \\
\text { (Level) }\end{array}$} \\
\cline { 2 - 6 } \cline { 6 - 9 } Level & $\begin{array}{c}\text { Point } \\
\text { estimate }\end{array}$ & $\begin{array}{c}\text { Standard } \\
\text { error }\end{array}$ & & 1 & 2 & 3 & 4 & 5 \\
$(1)$ & $(2)$ & $(3)$ & & $(4)$ & $(5)$ & $(6)$ & $(7)$ & $(8)$ \\
\hline 1 & 53.241 & 11.851 & 1.405 & -0.254 & -0.122 & -0.484 & -0.544 \\
2 & 3.397 & 3.712 & & 0.138 & 0.016 & 0.061 & 0.040 \\
3 & -9.045 & 2.027 & & & 0.041 & 0.025 & 0.040 \\
4 & -21.451 & 4.333 & & & & 0.188 & 0.210 \\
5 & -26.142 & 5.043 & & & & & 0.254 \\
\hline
\end{tabular}

Note: All entries are to be divided by 100 . 
TABLE 7

DIFFERENCES IN PAY PARITY MATRICES,

ACADEMIC EXECUTIVES, AUSTRALIAN UNIVERSITIES, 2005

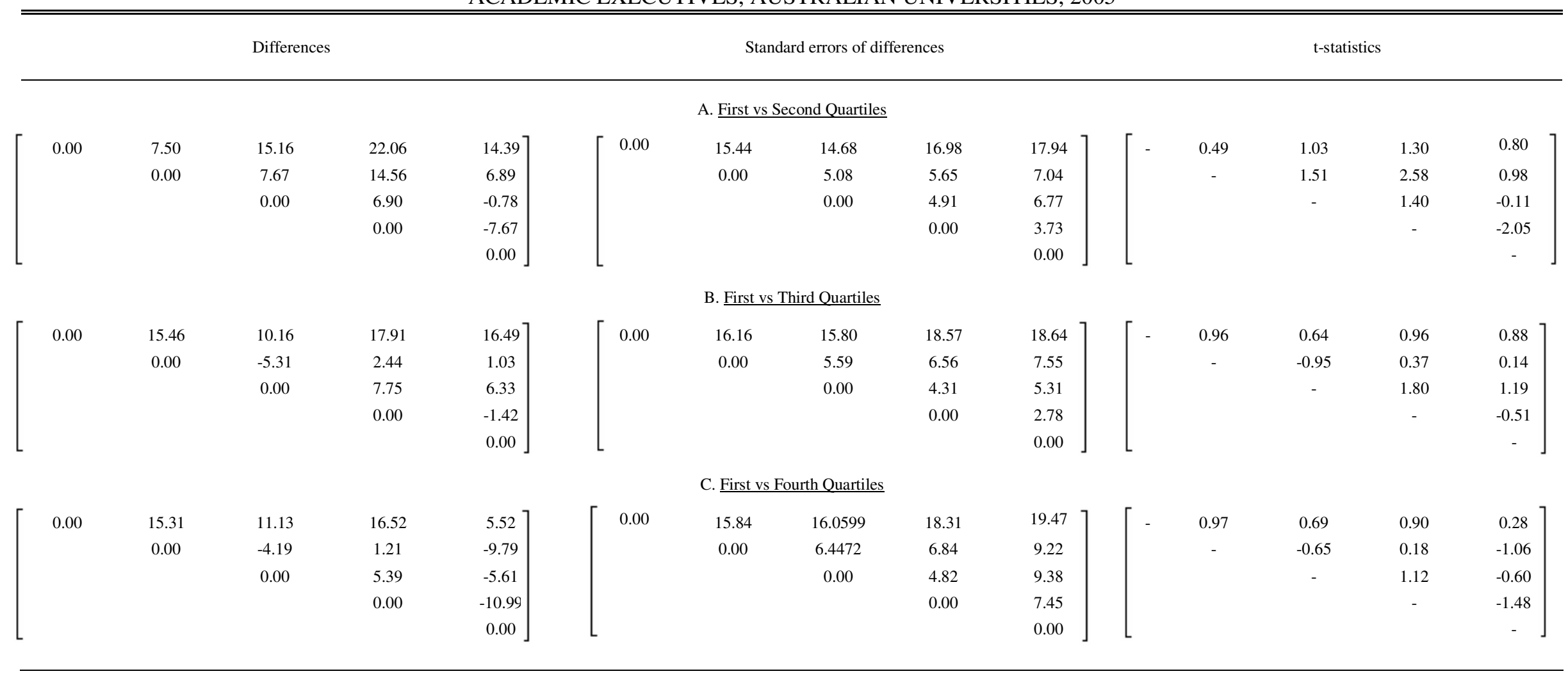

(Continued on next page) 
TABLE 7 (Continued)

TESTS OF DIFFERENCES IN PAY PARITY MATRICES,

ACADEMIC EXECUTIVES, AUSTRALIAN UNIVERSITIES, 2005

Differences

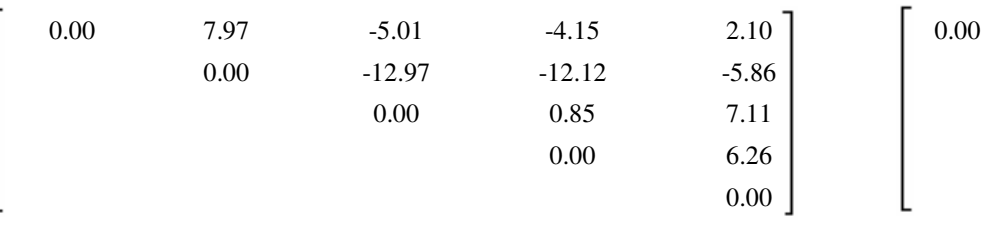

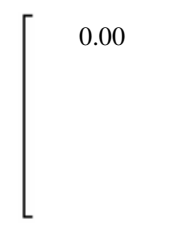

7.81

$\begin{array}{cc}-4.04 & -5.54 \\ -11.85 & -13.36 \\ 0.00 & -1.50 \\ & 0.00\end{array}$

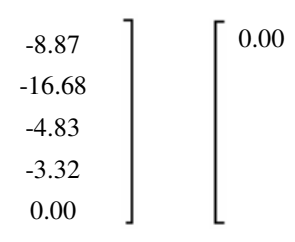

E. Second vs Fourth Quartiles

$\left[\begin{array}{ccccc}0.00 & -0.15 & 0.97 & -1.39 & -10.97 \\ & 0.00 & 1.121 & -1.24 & -10.82 \\ & & 0.00 & -2.36 & -11.94 \\ & & 0.00 & -9.58 \\ & & & & 0.00\end{array}\right]$

Note: 1. The rows and columns of each matrix refer to levels of remuneration. 2. Except for the t-statistics, all entries are to be divided by 100 . t-statistics

\section{Second vs Third Quartiles}

$\begin{array}{ccc}9.47 & 11.26 & 11.01 \\ 0.00 & 5.27 & 5.85 \\ & 0.00 & 2.63 \\ & & 0.00\end{array}$

$\left.\begin{array}{l}10.95 \\ 6.63 \\ 5.57 \\ 4.16 \\ 0.00\end{array}\right][$

-0.44
-2.46
-

$\left.\begin{array}{cc}-0.38 & 0.19 \\ -2.07 & -0.88 \\ 0.32 & 1.28 \\ - & 1.51 \\ & -\end{array}\right]$

$\begin{array}{lll}8.91 & 11.64 & 10.57 \\ 0.00 & 6.17 & 6.15 \\ & 0.00 & 3.40 \\ & & 0.00\end{array}$

F. Third vs Fourth Quartiles

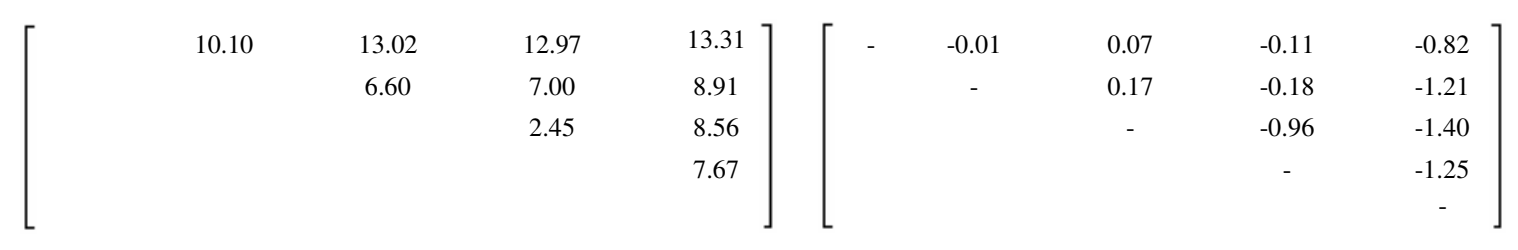

\begin{tabular}{|c|c|c|c|c|c|}
\hline 12.31 & - & 0.88 & -0.35 & -0.52 & -0.72 \\
\hline 8.49 & & - & -1.92 & -2.17 & -1.97 \\
\hline 9.53 & & & - & -0.44 & -0.51 \\
\hline 8.07 & & & & - & -0.41 \\
\hline 0.00 & _. & & & & - \\
\hline
\end{tabular}




\begin{tabular}{|c|c|c|}
\hline \multicolumn{3}{|c|}{$\begin{array}{c}\text { ECONOMICS DISCUSSION PAPERS } \\
2009\end{array}$} \\
\hline $\begin{array}{l}\text { DP } \\
\text { NUMBER }\end{array}$ & AUTHORS & TITLE \\
\hline 09.01 & Le, A.T. & $\begin{array}{l}\text { ENTRY INTO UNIVERSITY: ARE THE CHILDREN OF } \\
\text { IMMIGRANTS DISADVANTAGED? }\end{array}$ \\
\hline 09.02 & $\mathrm{Wu}, \mathrm{Y}$. & CHINA'S CAPITAL STOCK SERIES BY REGION AND SECTOR \\
\hline 09.03 & Chen, M.H. & $\begin{array}{l}\text { UNDERSTANDING WORLD COMMODITY PRICES RETURNS, } \\
\text { VOLATILITY AND DIVERSIFACATION }\end{array}$ \\
\hline 09.04 & Velagic, R. & UWA DISCUSSION PAPERS IN ECONOMICS: THE FIRST 650 \\
\hline 09.05 & McLure, M. & $\begin{array}{l}\text { ROYALTIES FOR REGIONS: ACCOUNTABILITY AND } \\
\text { SUSTAINABILITY }\end{array}$ \\
\hline 09.06 & Chen, A. and Groenewold, N. & $\begin{array}{l}\text { REDUCING REGIONAL DISPARITIES IN CHINA: AN } \\
\text { EVALUATION OF ALTERNATIVE POLICIES }\end{array}$ \\
\hline 09.07 & Groenewold, N. and Hagger, A. & $\begin{array}{l}\text { THE REGIONAL ECONOMIC EFFECTS OF IMMIGRATION: } \\
\text { SIMULATION RESULTS FROM A SMALL CGE MODEL. }\end{array}$ \\
\hline 09.08 & Clements, K. and Chen, D. & AFFLUENCE AND FOOD: SIMPLE WAY TO INFER INCOMES \\
\hline 09.09 & Clements, K. and Maesepp, M. & A SELF-REFLECTIVE INVERSE DEMAND SYSTEM \\
\hline 09.10 & Jones, C. & $\begin{array}{l}\text { MEASURING WESTERN AUSTRALIAN HOUSE PRICES: } \\
\text { METHODS AND IMPLICATIONS }\end{array}$ \\
\hline 09.11 & Siddique, M.A.B. & $\begin{array}{l}\text { WESTERN AUSTRALIA-JAPAN MINING CO-OPERATION: AN } \\
\text { HISTORICAL OVERVIEW }\end{array}$ \\
\hline 09.12 & Weber, E.J. & $\begin{array}{l}\text { PRE-INDUSTRIAL BIMETALLISM: THE INDEX COIN } \\
\text { HYPTHESIS }\end{array}$ \\
\hline 09.13 & McLure, M. & $\begin{array}{l}\text { PARETO AND PIGOU ON OPHELIMITY, UTILITY AND } \\
\text { WELFARE: IMPLICATIONS FOR PUBLIC FINANCE }\end{array}$ \\
\hline 09.14 & Weber, E.J. & $\begin{array}{l}\text { WILFRED EDWARD GRAHAM SALTER: THE MERITS OF A } \\
\text { CLASSICAL ECONOMIC EDUCATION }\end{array}$ \\
\hline 09.15 & Tyers, R. and Huang, L. & $\begin{array}{l}\text { COMBATING CHINA'S EXPORT CONTRACTION: FISCAL } \\
\text { EXPANSION OR ACCELERATED INDUSTRIAL REFORM }\end{array}$ \\
\hline 09.16 & $\begin{array}{l}\text { Zweifel, P., Plaff, D. and } \\
\text { Kühn, J. }\end{array}$ & $\begin{array}{l}\text { IS REGULATING THE SOLVENCY OF BANKS COUNTER- } \\
\text { PRODUCTIVE? }\end{array}$ \\
\hline 09.17 & Clements, K. & THE PHD CONFERENCE REACHES ADULTHOOD \\
\hline 09.18 & McLure, M. & $\begin{array}{l}\text { THIRTY YEARS OF ECONOMICS: UWA AND THE WA } \\
\text { BRANCH OF THE ECONOMIC SOCIETY FROM } 1963 \text { TO } 1992\end{array}$ \\
\hline 09.19 & Harris, R.G. and Robertson, P. & $\begin{array}{l}\text { TRADE, WAGES AND SKILL ACCUMULATION IN THE } \\
\text { EMERGING GIANTS }\end{array}$ \\
\hline 09.20 & $\begin{array}{l}\text { Peng, J., Cui, J., Qin, F. and } \\
\text { Groenewold, N. }\end{array}$ & STOCK PRICES AND THE MACRO ECONOMY IN CHINA \\
\hline 09.21 & Chen, A. and Groenewold, N. & $\begin{array}{l}\text { REGIONAL EQUALITY AND NATIONAL DEVELOPMENT IN } \\
\text { CHINA: IS THERE A TRADE-OFF? }\end{array}$ \\
\hline
\end{tabular}




\begin{tabular}{|c|c|c|}
\hline \multicolumn{3}{|c|}{$\begin{array}{l}\text { ECONOMICS DISCUSSION PAPERS } \\
2010\end{array}$} \\
\hline $\begin{array}{l}\text { DP } \\
\text { NUMBER }\end{array}$ & AUTHORS & TITLE \\
\hline 10.01 & Hendry, D.F. & $\begin{array}{l}\text { RESEARCH AND THE ACADEMIC: A TALE OF } \\
\text { TWO CULTURES }\end{array}$ \\
\hline 10.02 & McLure, M., Turkington, D. and Weber, E.J. & A CONVERSATION WITH ARNOLD ZELLNER \\
\hline 10.03 & $\begin{array}{l}\text { Butler, D.J., Burbank, V.K. and } \\
\text { Chisholm, J.S. }\end{array}$ & $\begin{array}{l}\text { THE FRAMES BEHIND THE GAMES: PLAYER'S } \\
\text { PERCEPTIONS OF PRISONER'S DILEMMA, } \\
\text { CHICKEN, DICTATOR, AND ULTIMATUM GAMES }\end{array}$ \\
\hline 10.04 & Harris, R.G., Robertson, P.E. and Xu, J.Y. & $\begin{array}{l}\text { THE INTERNATIONAL EFFECTS OF CHINA'S } \\
\text { GROWTH, TRADE AND EDUCATION BOOMS }\end{array}$ \\
\hline 10.05 & Clements, K.W., Mongey, S. and Si, J. & $\begin{array}{l}\text { THE DYNAMICS OF NEW RESOURCE PROJECTS } \\
\text { A PROGRESS REPORT }\end{array}$ \\
\hline 10.06 & Costello, G., Fraser, P., Groenewold, N. & $\begin{array}{l}\text { HOUSE PRICES, NON-FUNDAMENTAL } \\
\text { COMPONENTS AND INTERSTATE SPILLOVERS: } \\
\text { THE AUSTRALIAN EXPERIENCE }\end{array}$ \\
\hline 10.07 & Clements, $\mathrm{K}$. & $\begin{array}{l}\text { REPORT OF THE } 2009 \text { PHD CONFERENCE IN } \\
\text { ECONOMICS AND BUSINESS }\end{array}$ \\
\hline 10.08 & Robertson, P.E. & $\begin{array}{l}\text { INVESTMENT LED GROWTH IN INDIA: HINDU } \\
\text { FACT OR MYTHOLOGY? }\end{array}$ \\
\hline 10.09 & Fu, D., Wu, Y., Tang, Y. & $\begin{array}{l}\text { THE EFFECTS OF OWNERSHIP STRUCTURE AND } \\
\text { INDUSTRY CHARACTERISTICS ON EXPORT } \\
\text { PERFORMANCE }\end{array}$ \\
\hline 10.10 & $\mathrm{Wu}, \mathrm{Y}$. & $\begin{array}{l}\text { INNOVATION AND ECONOMIC GROWTH IN } \\
\text { CHINA }\end{array}$ \\
\hline 10.11 & Stephens, B.J. & $\begin{array}{l}\text { THE DETERMINANTS OF LABOUR FORCE } \\
\text { STATUS AMONG INDIGENOUS AUSTRALIANS }\end{array}$ \\
\hline 10.12 & Davies, M. & $\begin{array}{l}\text { FINANCING THE BURRA BURRA MINES, SOUTH } \\
\text { AUSTRALIA: LIQUIDITY PROBLEMS AND } \\
\text { RESOLUTIONS }\end{array}$ \\
\hline 10.13 & Tyers, R., Zhang, Y. & APPRECIATING THE RENMINBI \\
\hline 10.14 & Clements, K.W., Lan, Y., Seah, S.P. & $\begin{array}{l}\text { THE BIG MAC INDEX TWO DECADES ON } \\
\text { AN EVALUATION OF BURGERNOMICS }\end{array}$ \\
\hline 10.15 & Robertson, P.E., Xu, J.Y. & $\begin{array}{l}\text { IN CHINA'S WAKE: } \\
\text { HAS ASIA GAINED FROM CHINA'S GROWTH? }\end{array}$ \\
\hline 10.16 & Clements, K.W., Izan, H.Y. & $\begin{array}{l}\text { THE PAY PARITY MATRIX: A TOOL FOR } \\
\text { ANALYSING THE STRUCTURE OF PAY }\end{array}$ \\
\hline 10.17 & Gao, G. & WORLD FOOD DEMAND \\
\hline 10.18 & $\mathrm{Wu}, \mathrm{Y}$ & $\begin{array}{l}\text { INDIGENOUS INNOVATION IN CHINA: } \\
\text { IMPLICATIONS FOR SUSTAINABLE GROWTH }\end{array}$ \\
\hline 10.19 & Robertson, P.E. & DECIPHERING THE HINDU GROWTH EPIC \\
\hline
\end{tabular}

